\title{
Influence of the Initial Fiber Orientation on the Weld Strength in Welding of Glass Fiber Reinforced Thermoplastics
}

\author{
Isabel Fiebig and Volker Schoeppner \\ Kunststoffechnik Paderborn, Paderborn University, 33098 Paderborn, Germany \\ Correspondence should be addressed to Isabel Fiebig; isabel.fiebig@ktp.upb.de
}

Received 30 May 2016; Accepted 5 September 2016

Academic Editor: De-Yi Wang

Copyright ( 2016 I. Fiebig and V. Schoeppner. This is an open access article distributed under the Creative Commons Attribution License, which permits unrestricted use, distribution, and reproduction in any medium, provided the original work is properly cited.

\begin{abstract}
The welding factors are significantly lower in welding of fiber reinforced thermoplastics than in welding of unreinforced thermoplastics due to the fiber orientation in the weld. This paper presents results from investigations on the influence of the initial fiber orientation on the weld strength in hot plate and vibration welding for glass fiber reinforced polypropylene and polyamide 6. Injection molded specimens are compared to specimens with main initial fiber orientation being longitudinal and transverse to the joining direction. The results of CT analysis of the fiber orientation in the weld show the opportunity to achieve a higher weld strength by using specimens with fibers being initially oriented longitudinally to the joining direction. The influence of the initial fiber orientation in the parts to be welded on the weld strength in hot plate welding is more distinct than in vibration welding.
\end{abstract}

\section{Introduction}

The fields of application for fiber reinforced plastics are increasing especially due to their high potential for lightweight design. The combination of high strength and stiffness and low density enables the growing use of fiber composites [1]. A negative aspect is the anisotropy of the material properties. Fibers only have a reinforcing effect when they are aligned to the load direction. Perpendicular to the load direction, the matrix has to provide the complete elongation which results in high local stresses. Therefore, fibers being oriented transversely to the load direction might even weaken the matrix [2].

In the manufacture of plastic and composite components, joining is an important step. During the welding process, the surfaces of the parts to be welded are molten, for example, by contact to a heated tool. The molten surfaces are pressed together in the next step. In this joining phase, melt flow occurs at the interface. By cooling the weld is finally formed [3].

In welding of fiber reinforced materials, the attainable weld strength is low compared to the material strength of the reinforced material. The welding factor which is defined as the weld strength relative to the strength of the nonwelded reference sample is much smaller than one. Bruessel, for example, achieved a welding factor of 0.6 in hot plate welding of polypropylene (PP) reinforced with $30 \%$ short glass fibers. For polyamide (PA) reinforced with $30 \%$ short glass fibers the highest welding factor was 0.5 . The welding factor decreases with increasing fiber content [4]. Kagan realized a welding factor of 0.39 in vibration welding of glass fiber reinforced PA6 with 45\% fiber content [5]. Gehde et al. published results of investigations on welding of PP reinforced with $25 \%$ random glass mat. The welding factor was 0.42 in hot plate welding and 0.14 up to 0.35 in vibration welding [6]. Conversely, in welding of unreinforced plastics welding factors of one are attainable $[4,7]$.

The reason for the low welding factors in welding of fiber reinforced materials is connected to the fiber orientation in the weld. Fibers are oriented perpendicularly to the joining direction. Figure 1 shows the flow rate profiles in squeeze flow and the resulting fiber orientation in the weld. Due to squeeze flow, a reorientation of fibers occurs in the joining phase $[4,6,8,9]$. Since the fibers are not aligned in the load direction which corresponds to the joining direction, there is no reinforcing effect of the fibers in the weld.

Various investigations have been conducted on possibilities to prevent fiber orientation being perpendicular to 


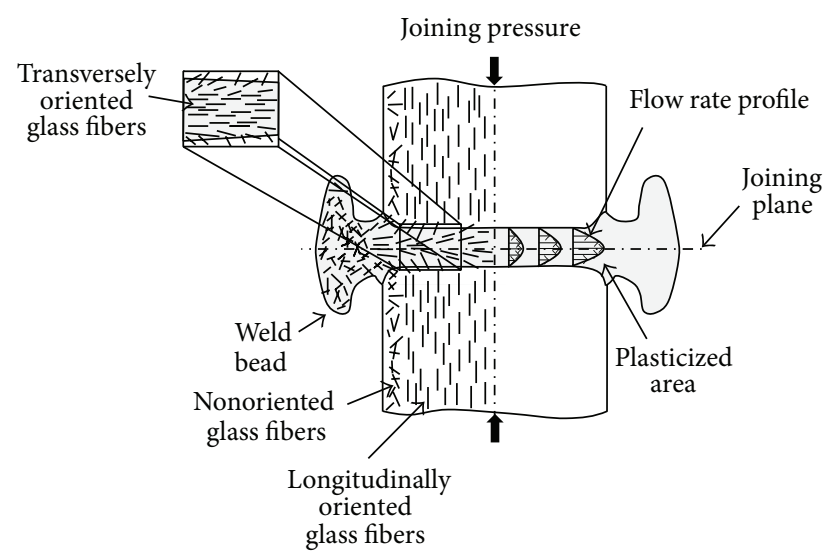

FIGURE 1: Schematic representation of the reorientation of fibers in the weld due to squeeze flow [4].

the load direction in welds and thereby to attain higher welding factors in welding of fiber reinforced thermoplastics $[4,6,10-12]$. One investigated influencing factor is the fiber orientation in the nonwelded part which is referred to as initial fiber orientation hereafter. Bucknall et al. compared weld strengths for initial fiber orientation parallel and perpendicular to the joining direction in hot plate welding of glass fiber reinforced PP. There is no difference in the highest weld strength attained for both initial fiber orientations. The authors explain this with the similar fiber orientation in the weld independent of the fiber orientation before welding [8]. The results of Kagan et al. indicate that in vibration welding of glass fiber reinforced PA6 and PA66 the reinforcing effect of the fiber in the weld is independent of the fiber orientation in the parts to be welded [10]. Other investigations did not show such distinct results. At the Süddeutsche KunststoffZentrum (SKZ) in Würzburg, injection molded semitensile bars were prepared to attain an initial fiber orientation being longitudinal to the joining direction. Therefore, the end of the flow path of a semitensile bars was sawn off. The sawn surface was used as the surface to be joined in hot plate and infrared welding. The weld strength achieved with injection molded parts was compared to the weld strength attained with sawn parts for polypropylene (PP), polyamide 6 (PA6), and acrylonitrile butadiene styrene (ABS) reinforced with up to $40 \%$ short glass fibers. Initial fiber orientation longitudinal to the joining direction of the sawn parts does not distinctly result in higher weld strength. For example, the weld strength in hot plate welding of sawn parts of PA6 is higher than that of injection molded parts for fiber contents of $25 \%$ and $40 \%$ but lower for fiber content of $15 \%$ [7].

Although high efforts have been made in researching the welding of fiber reinforced thermoplastics, there is still no solution for the general challenge of low welding factors. Therefore, current investigations at the Kunststofftechnik Paderborn (KTP) deal with the possibility of improving the reinforcing effect of fibers in the weld. This paper presents results from investigations on the influence of the initial fiber orientation on the weld strength in hot plate and vibration welding for glass fiber reinforced polypropylene

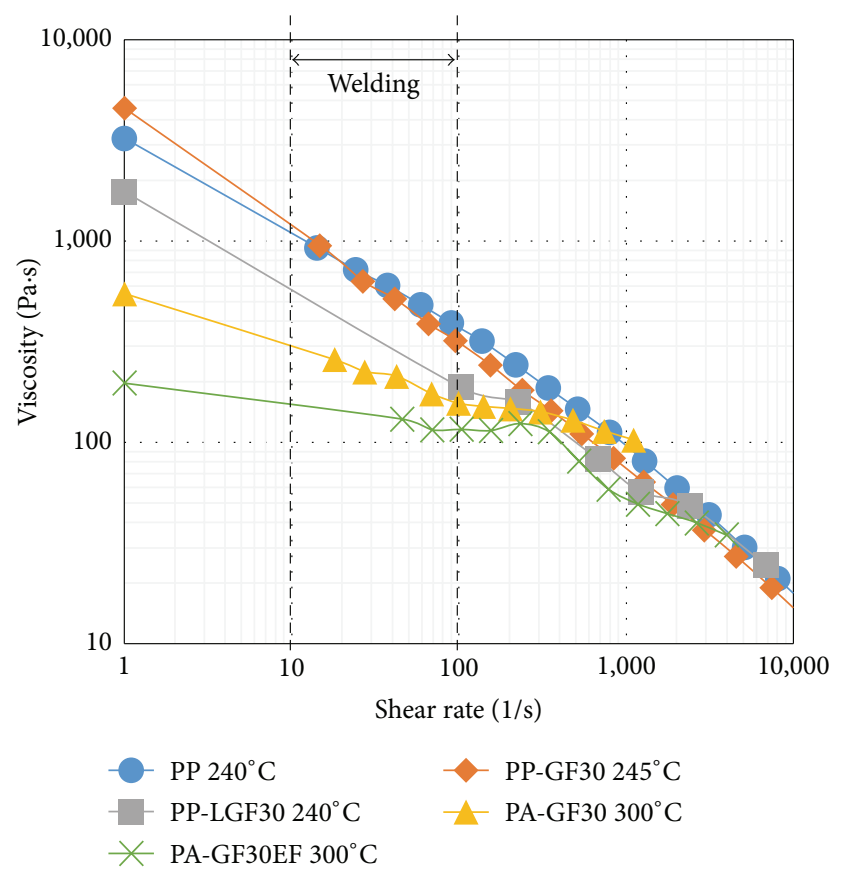

Figure 2: Viscosity curves.

and polyamide 6 . The aim is to determine the potential of a specific fiber orientation in the joining direction before welding.

\section{Materials and Methods}

2.1. Materials. Five materials were used to produce joining parts by injection molding. Three types of polypropylene were chosen to identify the effect of short and long glass fibers in welding: unreinforced PP homopolymer (Moplen HP 501 L, LyondellBasell), short glass fiber reinforced PP with 30\% fiber content (Altech NXT PP-H A 2030-450 GF30 CP, Albis), and long glass fiber reinforced PP with 30\% fiber content (TechnoFiber PP LGF 30-10-01 L HI, TechnoCompound). For investigations on the effect of the viscosity of polyamides, two types of glass fiber reinforced polyamide 6 with $30 \%$ fiber content differing in viscosity properties were used: polyamide with improved flowability and therefore low melt viscosity (Durethan BKV $30 \mathrm{H} 2.0 \mathrm{EF}$ ) and polyamide with improved weldability in hot plate and vibration welding because of higher melt viscosity in shear rate ranges relevant to welding (Durethan BKV $330 \mathrm{H} 2.0$, Lanxess). Figure 2 depicts viscosity curves for the materials used, determined with a high pressure capillary rheometer (Rheograph 2002, Goettfert) for common welding temperatures.

2.2. Quantification of Fiber Orientation. In 1987, Advani and Tucker proposed an alternative method to the probability distribution function for the description of fiber orientation [13]. In the proposed method, the fiber orientation is described by a three-dimensional fiber orientation tensor. The basis for this description is the definition of the orientation of a single rigid 


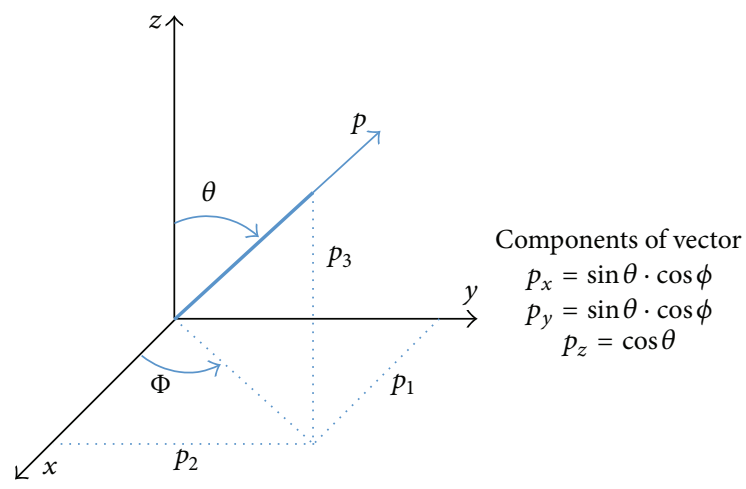

FIGURE 3: Description of fiber orientation by two angles [13].

cylindrical fiber in three-dimensional space by two angles (Figure 3).

Based on the formulation of a unit vector $P$ with the Cartesian components $p_{1}, p_{2}$, and $p_{3}$, the orientation tensor $a_{i j}$ can be created. The components of the orientation tensor are dyadic products of the vector $P$; for example, $a_{x x}=p_{x} \cdot p_{x}$.

\section{Orientation Tensor}

$$
a_{i j}=\left(\begin{array}{ccc}
a_{x x} & a_{y x} & a_{z x} \\
a_{x y} & a_{y y} & a_{z y} \\
a_{x z} & a_{y z} & a_{z z}
\end{array}\right) .
$$

The components on the principle diagonal of the orientation tensor $\left(a_{x x}, a_{y y}, a_{z z}\right)$ represent the orientation in $x$-, $y$-, and $z$-direction. The sum of these values is 1 . The values of the components of the orientation tensor may represent orientation of a single fiber or average values for several fibers. A uniform fiber orientation in $x$-direction, for example, is represented by $a_{x x}$ equal to 1 while $a_{y y}$ and $a_{z z}$ equal 0 . The components $a_{i j}$ with $i \neq j$ represent the tilt of orientation in several planes. Since there is no additional information by including these components in the analysis in these investigations, the components on the principle diagonal are sufficient for analysis of the main fiber orientation here [14, $15]$.

For the analysis of the fiber orientation in the parts to be welded and in the weld, computed tomography (CT) is used. This method provides three-dimensional recording of a scanned part. Materials and regions with different densities are identified. The detection of fibers is realized by analysis of grey value gradients. For the investigations a phoenix nanotom s (GE sensing) was used.

2.3. Specimen Preparation. The parts have been manufactured in injection molding. Plates with dimensions of $60 \mathrm{~mm}$ $\times 60 \mathrm{~mm} \times 2 \mathrm{~mm}$ (plate 1 ) were injection molded for hot plate welding. For vibration welding, plates of dimensions $130 \mathrm{~mm}$ $\times 70 \mathrm{~mm} \times 3 \mathrm{~mm}$ (plate 2 ) were injection molded. The different sample thicknesses are connected to the different welding methods. To be able to use the vibration welding machine (see Section 2.4) in an appropriate range of the welding force, a part thickness higher than $2 \mathrm{~mm}$ was required. The influence

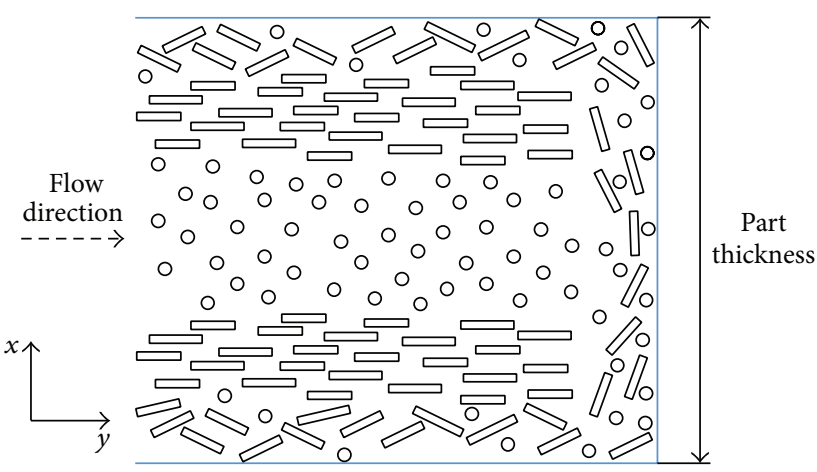

FIGURE 4: Fiber orientation in an injection molded plate depicted schematically.

of the part thickness on the fiber orientation is subordinate here. More decisive for the resulting fiber orientation are the two different injection molding tools with different gating systems $[16,17]$.

Without any further preparation, these plates have been welded at the end of the injection molding flow path for determining the weld strength for parts with standard fiber orientation resulting from injection molding (Figure 6, left). The fiber orientation in the flow channel and at the end of the flow path in injection molded parts which results from the flow profile is shown schematically in Figure 4. In the middle of the part thickness, fibers are oriented transversely to the flow direction because of elongation flow. In the shearing zone near the walls fibers are aligned to the flow direction because of shear flow [18]. In the edge layer, fibers are oriented statistically. At the end of the flow channel fibers have a disordered orientation. The preference orientation is transverse to the flow direction $[16,19]$.

By CT analysis, the fiber orientation can be described by the fiber orientation tensor (see Section 2.2). Figure 5 shows the progress of the components of the fiber orientation tensor over the part ( $x$-axis) and the flow direction ( $y$-axis) which has been depicted in Figure 4 schematically (progress of the components of the fiber orientation tensor in $z$-direction is constant except for the edges). $a_{x x}, a_{y y}$, and $a_{z z}$ represent the fiber orientation in the directions of $x$ (part thickness and direction of squeeze flow in welding), $y$ (flow direction in injection molding and joining direction in welding), and $z$ (direction of specimen width and vibration direction in vibration welding). At the position of $3 \mathrm{~mm}$ from the end of the flow channel, $a_{z z}$ increases and $a_{y y}$ decreases while $a_{x x}$ is constant. Beginning at about $0.5 \mathrm{~mm}$ from the end of the flow path $a_{x x}$ starts to increase and $a_{z z}$ starts to decrease. It is obvious that, at the end of the flow path, where the weld zone is placed usually, the orientation in joining direction $\left(a_{y y}\right)$ is very low. This indicates that it is hard to realize a high orientation in joining direction (equal to load direction) in the weld. Therefore, plates are prepared before welding in order to create joining parts with defined fiber orientation being longitudinal and transverse to the joining direction (Figure 6, middle and right). 

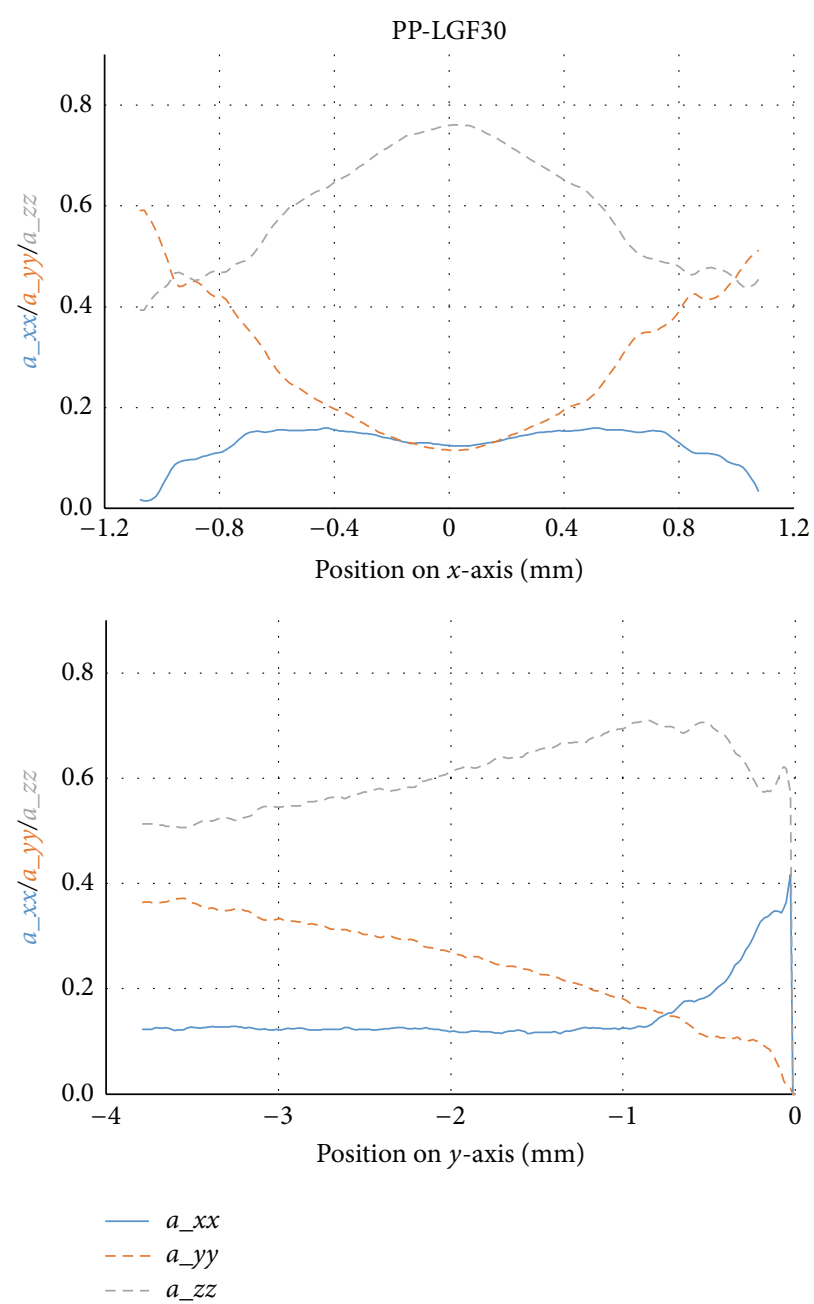

FIGURE 5: Progress of the fiber orientation along the $x$ - and $y$-axis in an injection molded plate of PP-LGF30.

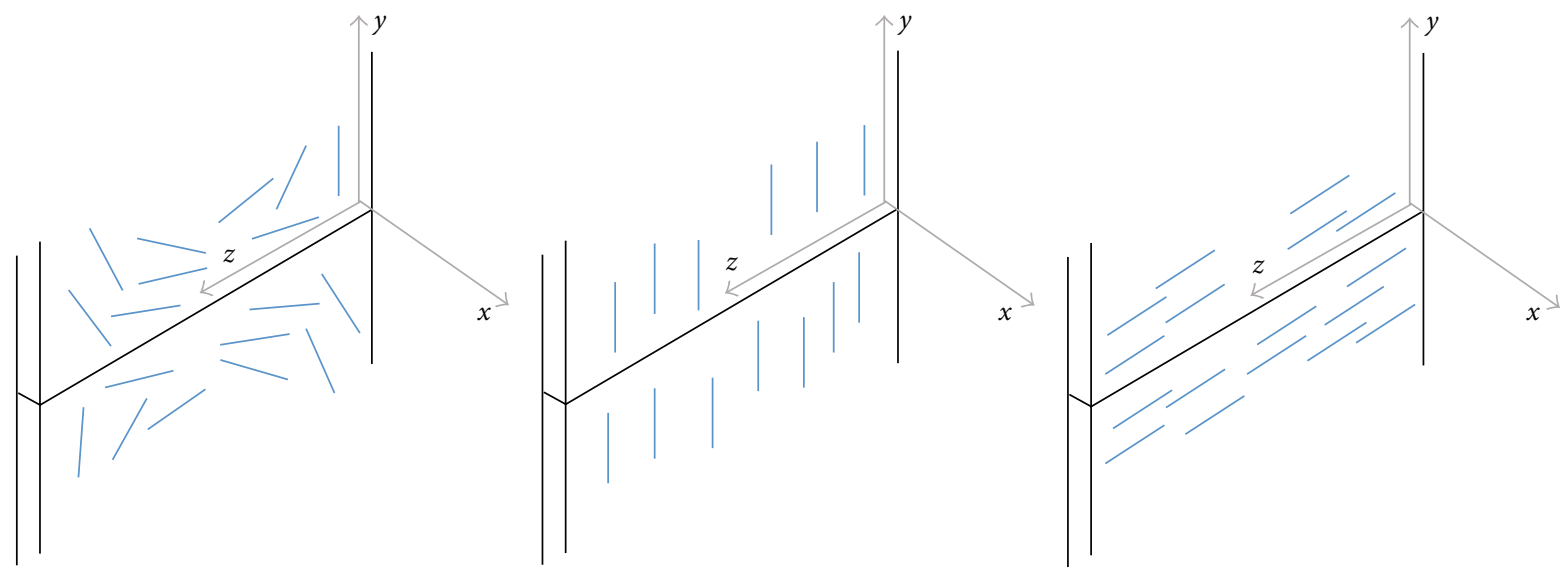

FIGURE 6: Schematic representation of welding samples with different fiber orientations.

Figure 7 shows images from the CT analysis of an injection molded plate of dimensions $60 \mathrm{~mm} \times 60 \mathrm{~mm} \times 2 \mathrm{~mm}$ of PP-LGF30. Fiber orientation is semicircular originating from the film gate. At the lateral edges, fibers are mainly oriented longitudinally to the flow direction. At the end of the flow path, fiber orientation is mainly perpendicular to the flow direction. Based on these results, the plates were prepared before welding by sawing. By cutting the plate in half along the flow direction and welding the cut surfaces of the half plates, the fibers at the cut surfaces are highly oriented in the 

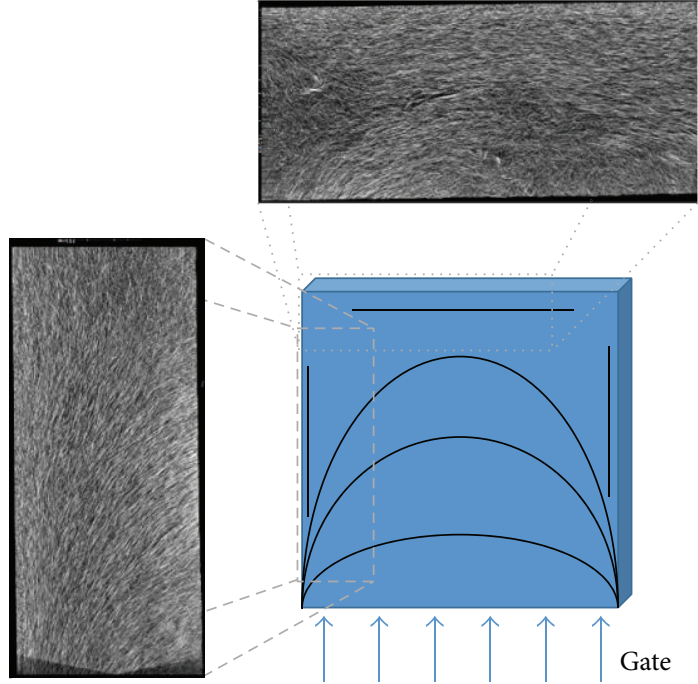

FIGURE 7: CT analysis of an injection molded plate of PP-LGF30.
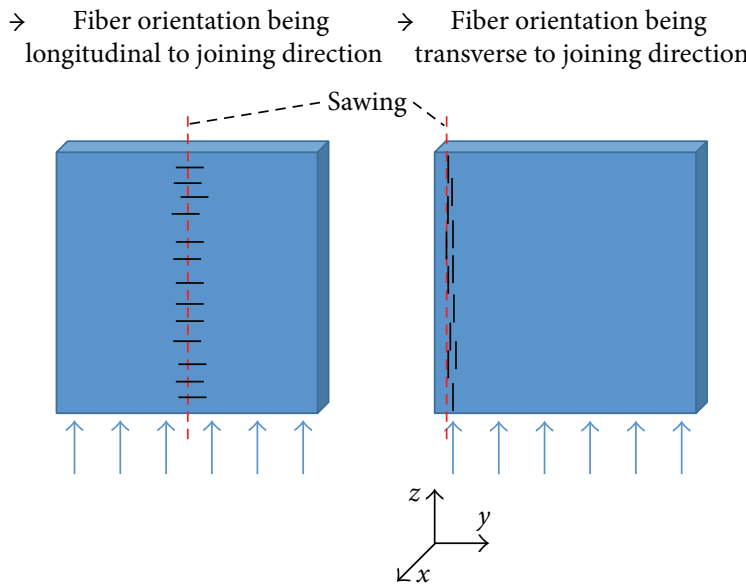

FIGURE 8: Schematic representation of the preparation of plates before welding.

joining direction (Figure 8). By cutting off about 3 to $4 \mathrm{~mm}$ from the lateral edge of the plate, in the cut surface, a fiber orientation perpendicular to the joining direction is created. The cut surface represents the surface to be joined.

Figure 9 depicts the fiber orientation in the joining area in a plate sawn as shown in Figure 8 on the left. The orientation in the joining direction $\left(a_{y y}\right)$ with 0.43 is quite high compared to a part after injection molding (Figure 5). In Figure 10 the fiber orientation at the lateral edge of an injection molded plate is depicted. It is obvious that the fiber orientation is constant from about $2 \mathrm{~mm}$ from the edge. Therefore, as described above, the lateral edge of the plate is cut off at 3 to $4 \mathrm{~mm}$ from the edge. In the joining area, the fibers are mainly oriented in $z$-direction while $a_{y y}$ and $a_{x x}$ are at the same low level.

When examining the progress of the fiber orientation over the $x$-axis, it is obvious that the fiber orientation is not constant due to the flow profile. Therefore, the fiber
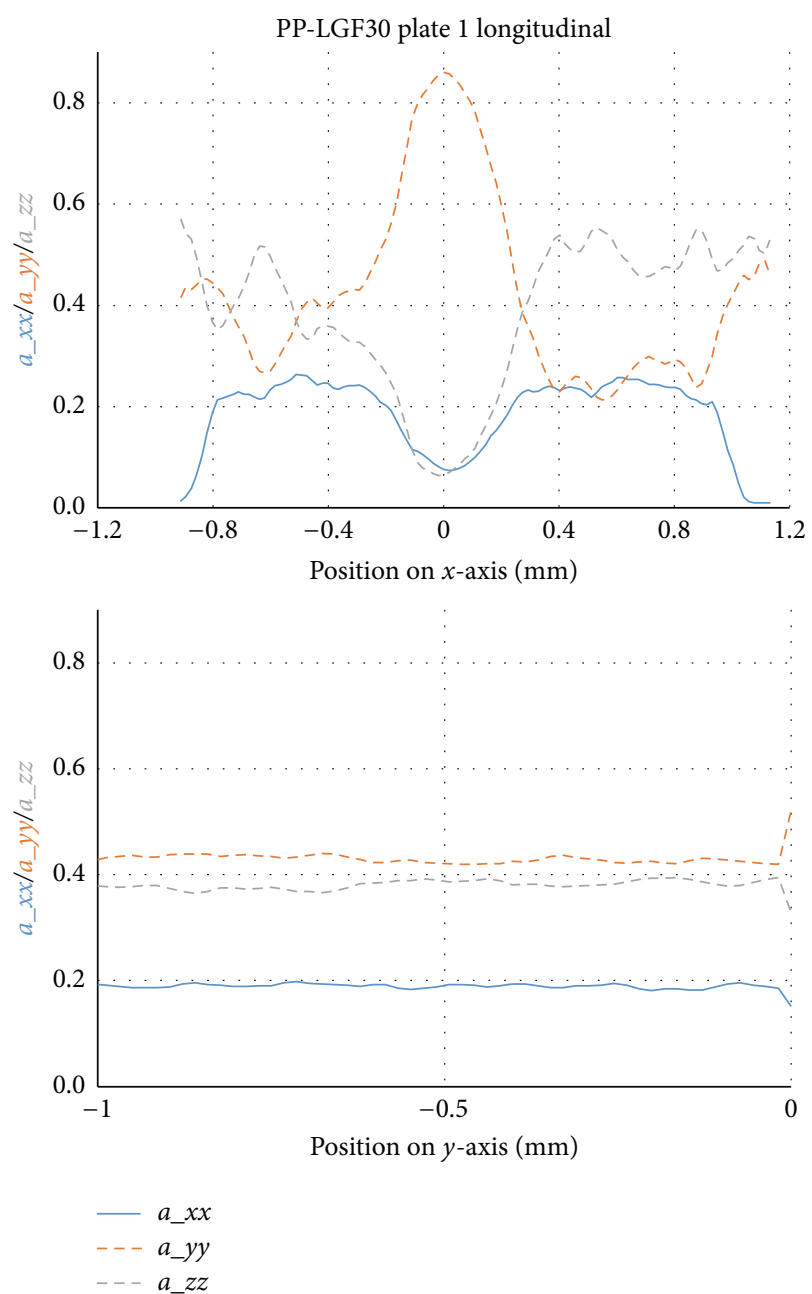

FIgURE 9: Progress of the fiber orientation along the $x$-and $y$-axis in a plate of PP-LGF30 with initial fiber orientation being longitudinal to the joining direction (hot plate welding).

TABLE 1: Fiber orientation in parts to be joined by hot plate welding.

3D fiber

Material and initial fiber orientation orientation tensor

\begin{tabular}{ccccc} 
& & $a_{x x}$ & $a_{y y}$ & $a_{z z}$ \\
\hline \multirow{3}{*}{ PP-GF30 } & Injection molded & 0.26 & 0.19 & 0.55 \\
& Longitudinally oriented & 0.21 & $\mathbf{0 . 4 7}$ & 0.32 \\
& Transversely oriented & 0.19 & 0.22 & $\mathbf{0 . 5 9}$ \\
\hline \multirow{3}{*}{ PP-LGF30 } & Injection molded & 0.15 & 0.17 & 0.68 \\
& Longitudinally oriented & 0.19 & $\mathbf{0 . 4 3}$ & 0.39 \\
& Transversely oriented & 0.15 & 0.16 & $\mathbf{0 . 6 9}$ \\
\hline
\end{tabular}

orientation tensor is determined at the positions along the $x$ axis: in the middle $(x=0 \cdot b)$ ( $b$ is the thickness of the part to be welded), at the transition to the bead $(x=1 \cdot 1 / 2 \cdot b)$, and in between $(x=0.5 \cdot 1 / 2 \cdot b)$. The average of three values is calculated for further analysis. In Table 1 , the average values for the components of the fiber orientation tensor are listed for short and long glass fiber reinforced PP for the three 

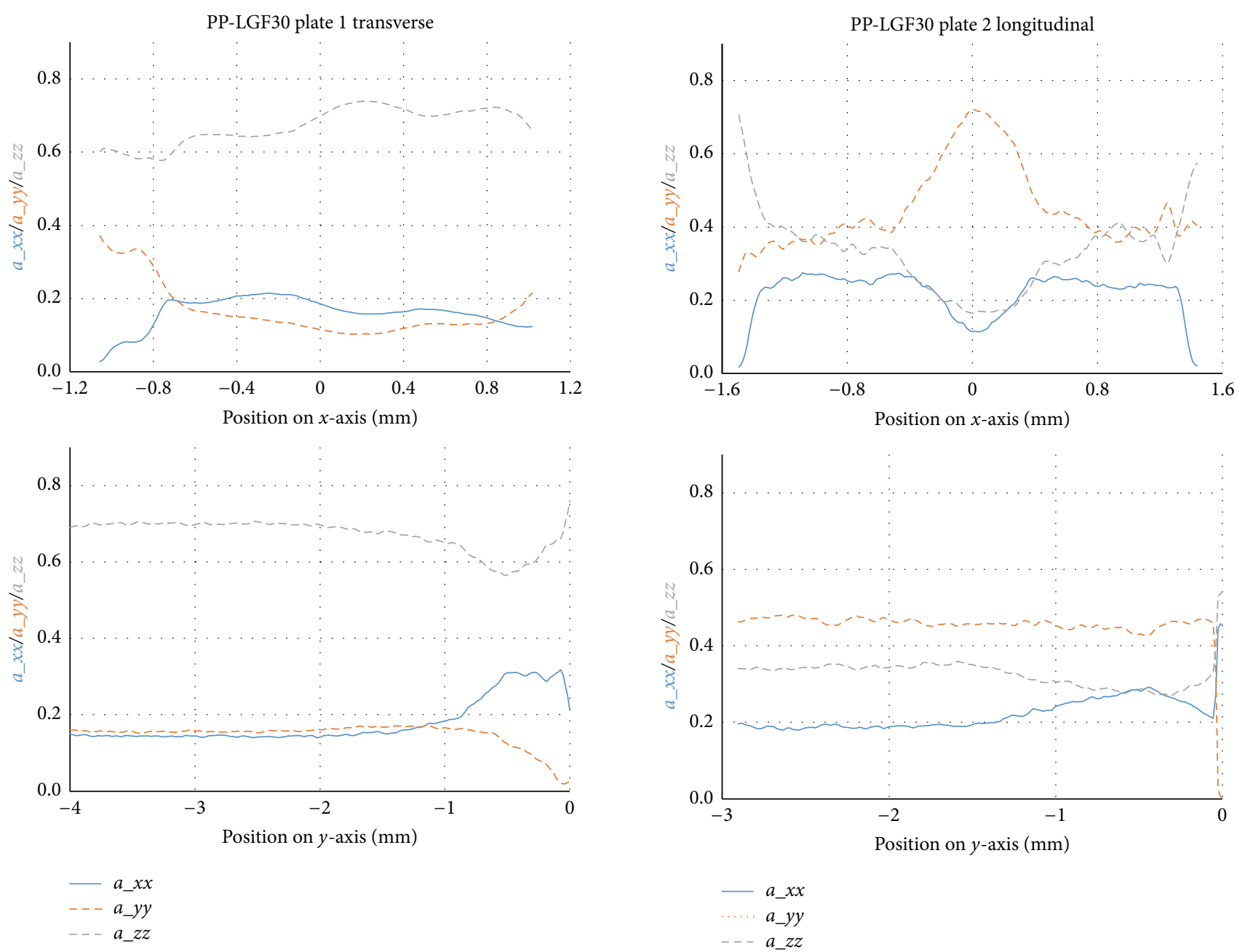

Figure 10: Progress of the fiber orientation along the $x$-and $y$-axis in a plate of PP-LGF30 with initial fiber orientation being transverse to the joining direction (hot plate welding).

different parts to be welded (Figure 6). The high values for $a_{y y}$ for the parts with fibers oriented longitudinally to the joining direction as well as the high values for $a_{z z}$ for the parts with fibers oriented transversely to the joining direction are highlighted in bold type.

The same procedure as described above for plates for hot plate welding has been performed for the injection molded plates for vibration welding. Analogous to hot plate welding, the components of the fiber orientation tensor for the three parts to be welded with different initial fiber orientation are listed in Table 2 for vibration welding.

Figure 11 depicts the fiber orientation in the joining area in a plate sawn as shown in Figure 8 on the left. The orientation in the joining direction $\left(a_{y y}\right)$ with 0.45 is quite high compared to a part after injection molding (Table 2). In Figure 12 the fiber orientation at the lateral edge of an injection molded plate is depicted. In the joining area at 3 to $4 \mathrm{~mm}$ from the edge, the fibers are mainly oriented in the $z$-direction while $a_{y y}$ and $a_{x x}$ are at a similar low level. Compared to the plates for hot plate welding (Figure 10)

Figure 11: Progress of the fiber orientation along the $x$ - and $y$-axis in a plate of PP-LGF30 with initial fiber orientation being longitudinal to the joining direction (vibration welding).

TABLE 2: Fiber orientation in parts to be joined by vibration welding.

\begin{tabular}{ccccc}
\hline \multirow{2}{*}{ Material and initial fiber orientation } & \multicolumn{3}{c}{ 3D fiber } \\
& & $a_{x x}$ & $a_{y y}$ & $a_{z z}$ \\
\hline \multirow{3}{*}{ PP-GF30 } & Injection molded & 0.17 & 0.14 & 0.69 \\
& Longitudinally oriented & 0.24 & $\mathbf{0 . 5 2}$ & 0.25 \\
& Transversely oriented & 0.24 & 0.32 & $\mathbf{0 . 4 5}$ \\
\hline \multirow{2}{*}{ PP-LGF30 } & Injection molded & 0.19 & 0.17 & 0.64 \\
& Longitudinally oriented & 0.22 & $\mathbf{0 . 4 5}$ & 0.33 \\
& Transversely oriented & 0.23 & 0.3 & $\mathbf{0 . 4 7}$ \\
\hline
\end{tabular}

the degree of orientation in the $z$-direction is not that high. These differences are connected to the different geometries, thicknesses, and injection molding tools of the two plates.

For determining the material strength, tensile bars of dimensions of the specimen type 1BA in DIN EN ISO 527-2 were milled from the specimens with length aligned with the flow direction of the melt in injection molding. The material strength was determined as described in Section 2.5. 

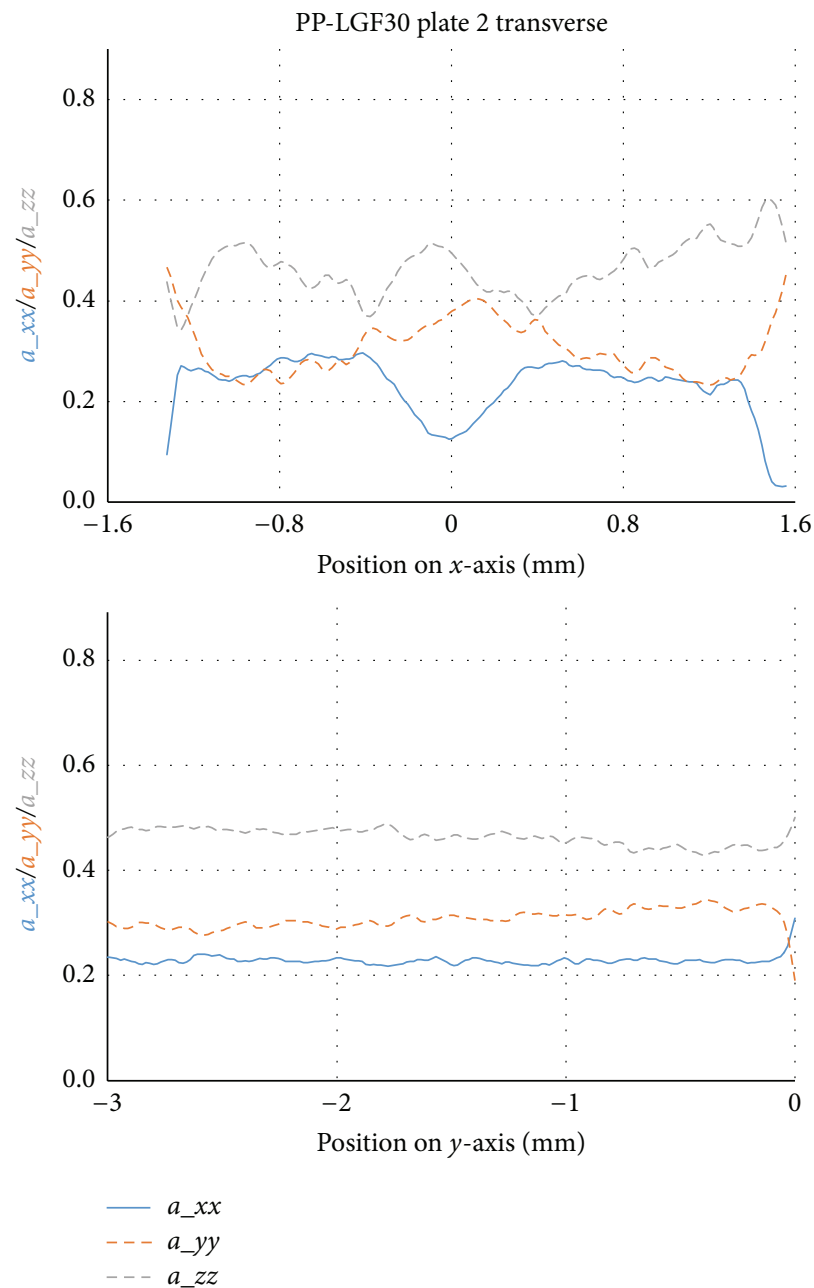

FIGURE 12: Progress of the fiber orientation along the $x$ - and $y$-axis in a plate of PP-LGF30 with initial fiber orientation being transverse to the joining direction (vibration welding).
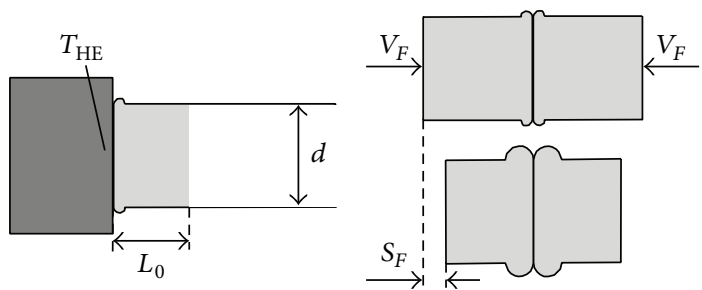

FIGURE 13: Selected process parameters in hot plate welding.

2.4. Welding. The welding examinations were conducted with the hot plate welding machine K2150 (Bielomatik Leuze $\mathrm{GmbH} \& \mathrm{Co} . \mathrm{KG})$. Selected important process parameters in hot plate welding are depicted in Figure 13. The parameters were varied according to Table 3 . Values on level 0 are based on recommended values by Kreiter, guidelines, and experience $[20,21]$. The melt layer thickness $L_{0}$ is the length of the molten area at the end of the heating phase in which the surfaces to be molten are heated in contact to a hot plate (temperature $\left.T_{\mathrm{HE}}\right) . L_{0}$ is described in relation to the part thickness $d$. The welding displacement $s_{F}$ that is described in relation to the melt layer thickness is realized by the welding velocity $v_{F}$. Other parameters like matching time, displacement, and cooling time were constant for all tests. Relevant parameter combinations for the following description of the conducted investigations are listed in Table 4. Each design point represents one parameter combination.

The examinations concerning vibration welding were conducted by the linear vibration welding machine LVW 2020 CPC (KLN Ultraschall AG). The maximum welding force is $4.7 \mathrm{kN}$. Figure 14 shows selected parameters in vibration welding. These parameters were varied according to Table 5. Values on level 0 are based on guidelines and experience $[22,23]$. The surfaces to be welded are pressed together by the welding pressure $p_{F 1}$. By a vibration movement with an amplitude $a$, the surface become molten due to friction. When the defined welding displacement $s_{F}$ is attained, the vibration stops and the welding process is completed after the cooling phase. In a welding process with a dual stage welding pressure, the second pressure $p_{F 2}$ is 
TABLE 3: Variation of welding parameters in hot plate welding.

\begin{tabular}{|c|c|c|c|}
\hline Factor & Level - & Level 0 & Level + \\
\hline Melt layer thickness relative to material thickness $L_{0} / d[-]$ & 0.2 & 0.34 & 0.48 \\
\hline Welding displacement relative to melt layer thickness $s_{F} / L_{0}[-]$ & 0.6 & 0.75 & 0.9 \\
\hline Joining velocity $v_{F}[\mathrm{~mm} / \mathrm{s}]$ & 1 & 5 & 9 \\
\hline Hot plate temperature $T_{\mathrm{HE}}\left[{ }^{\circ} \mathrm{C}\right]$ & $T_{M}+60 \mathrm{~K}$ & $T_{M}+80 \mathrm{~K}$ & $T_{M}+100 \mathrm{~K}$ \\
\hline
\end{tabular}

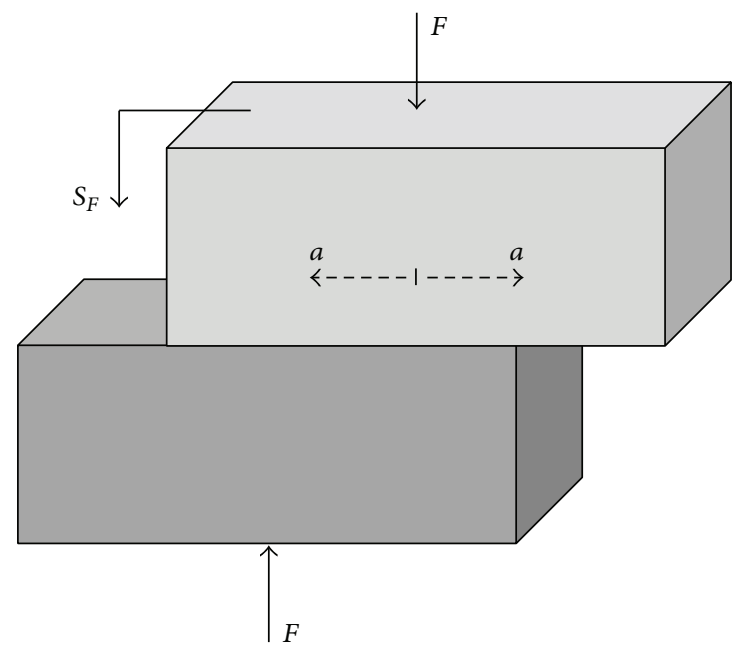

FIGURE 14: Selected process parameters in vibration welding.

TABLE 4: Selected design points in hot plate welding.

\begin{tabular}{lcccc}
\hline Design point & $L_{0} / d[-]$ & $s_{F} / L_{0}[-]$ & $v_{F}[\mathrm{~mm} / \mathrm{s}]$ & $T_{\mathrm{HE}}\left[{ }^{\circ} \mathrm{C}\right]$ \\
\hline I & 0.34 & 0.75 & 5 & $T_{M}+80 \mathrm{~K}$ \\
II & 0.2 & 0.6 & 1 & $T_{M}+60 \mathrm{~K}$ \\
III & 0.34 & 0.75 & 9 & $T_{M}+80 \mathrm{~K}$ \\
IV & 0.48 & 0.75 & 5 & $T_{M}+80 \mathrm{~K}$ \\
V & 0.48 & 0.9 & 9 & $T_{M}+100 \mathrm{~K}$ \\
VI & 0.34 & 0.75 & 5 & $T_{M}+100 \mathrm{~K}$ \\
\hline
\end{tabular}

chosen lower than the first one $p_{F 1}$. This enables a quick melting of the surface combined with a high melt layer thickness which results in a higher weld strength for some (unreinforced) materials. Other parameters like cooling time and vibration frequency were constant for all tests. Relevant parameter combinations for the following description of the conducted investigations are listed in Table 6. Each design point represents one parameter combination.

2.5. Tensile Test. For determination of the weld strength and the material strength, a tensile test according to DIN EN ISO 527 was conducted. The chosen testing speed for all materials was $20 \mathrm{~mm} / \mathrm{min}$. The vibration welded plates were cut into four pieces of $20 \mathrm{~mm}$ width to enable a fixation during the tensile test. A preparation of the hot plate welded tensile bars was not necessary before testing.

\section{Results and Discussion}

3.1. Effect on Weld Strength. The welding parameters in hot plate welding do not correlate to the weld strength of plates with different initial fiber orientation. Therefore, only two prominent design points for each material are considered in the following. Figure 15 shows the weld strength in hot plate welding of injection molded plates without any further preparation "inj. molded" compared to plates with initial fiber orientation longitudinally oriented (long. oriented) and transversely oriented to the joining direction (transv. oriented). The bars represent the mean value and the error bar represents the standard deviation. For short glass fiber reinforced PP and PA, the weld strength is highest for injection molded plates without any further preparation. In one case depicted for each material, the weld strength of plates with initial fiber orientation being longitudinal to the joining direction is higher than for plates with fibers oriented transversely to the joining direction in the parts before welding. The other design point for each material shows the opposite. In contrast, for long fiber reinforced PP, with longitudinal initial fiber orientation, a higher weld strength is attainable compared to injection molded plates without any further preparation. Compared to this, for plates with fibers being initially oriented transversely to the joining direction, the weld strength is significantly lower. The partly very high standard deviation can be ascribed to the preparation of the parts to be welded by a circular saw. Consequently, in hot 
TABLE 5: Variation of welding parameters in vibration welding.

\begin{tabular}{|c|c|c|c|}
\hline Factor & Level - & Level 0 & Level + \\
\hline Welding pressure $1 p_{F 1}[\mathrm{MPa}]$ & 0.5 & 2.25 & 4.0 \\
\hline Welding pressure 1 relative to welding pressure $2 p_{F 1} / p_{F 2}[-]$ & $1 / 1$ & $4.5 / 1$ & $8 / 1$ \\
\hline Welding displacement $s_{F}[\mathrm{~mm} / \mathrm{s}]$ & 0.4 & 0.9 & 1.4 \\
\hline Vibration amplitude $a[\mathrm{~mm}]$ & 0.5 & 0.75 & 1.0 \\
\hline
\end{tabular}

TABLE 6: Selected design points in vibration welding.

\begin{tabular}{lcccc}
\hline Design point & $p_{F 1}[\mathrm{MPa}]$ & $p_{F 1} / p_{F 2}[-]$ & $s_{F}[\mathrm{~mm} / \mathrm{s}]$ & $a[\mathrm{~mm}]$ \\
\hline I & 0.5 & $1 / 1$ & 0.4 & 0.5 \\
II & 4 & $1 / 1$ & 0.4 & 0.5 \\
III & 0.5 & $1 / 1$ & 1.4 & 0.5 \\
IV & 0.5 & $8 / 1$ & 1.4 & 0.5 \\
V & 4 & $1 / 1$ & 0.4 & 1.0 \\
VI & 4 & $8 / 1$ & 1.4 & 1.0 \\
\hline
\end{tabular}

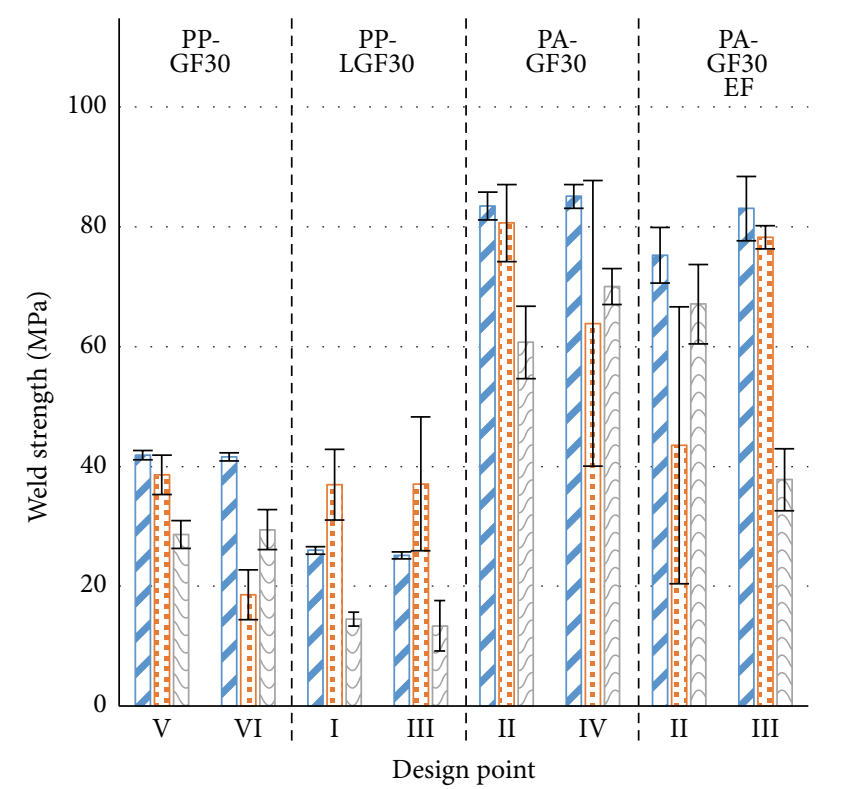

$$
\begin{aligned}
& \square \text { Injection molded } \\
& \text { ㄴ. Longitudinally oriented } \\
& \square \text { Transversely oriented }
\end{aligned}
$$

FIGURE 15: Weld strength in hot plate welding for different initial fiber orientations.

plate welding of long glass fiber reinforced materials, it is possible to attain significantly higher weld strength than for plates with fiber orientation resulting from injection molding in the end of the flow path.

Figure 16 shows the weld strength in vibration welding for design points that resulted in the highest and lowest weld strength for injection molded plates without any further preparation. The weld strength is being compared for different initial fiber orientations analogous to hot plate welding. PA-GF30EF does not react sensitively to different initial fiber orientations; the weld strength reaches a similar level when the high standard deviations are taken into account. Initial

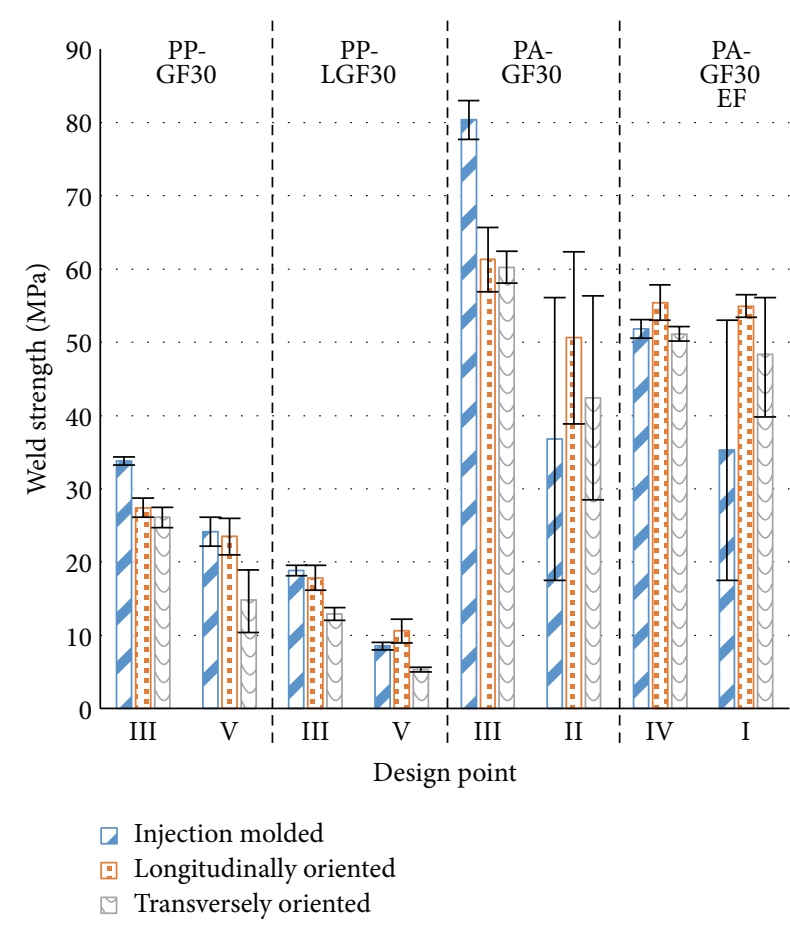

FIGURE 16: Weld strength in vibration welding for different initial fiber orientations.

transverse fiber orientation does not result in significantly different weld strength compared to initial longitudinal fiber orientation for short glass fiber reinforced materials. For PP-LGF30, one welding parameter combination results in a higher weld strength for plates with fibers being oriented initially longitudinally than for injection molded plates. But this difference is not significant. In vibration welding, it is consequently not possible to attain a significantly higher weld strength with a high proportion of fibers oriented longitudinally to the joining direction in parts to be welded. The difference in the attainable weld strength for initial fiber orientation being longitudinal to the joining direction compared to transverse initial fiber orientation is not as distinct as in hot plate welding.

Comparing the attained weld strength with the material strength (Table 7), the low welding factors become apparent. For short glass fiber reinforced materials, the highest welding factors in hot plate welding are attained for the fiber orientation resulting from injection molding: 0.61 for PP-GF30, 0.83 for PA-GF30, and 0.69 for PA-GF30EF. In contrast, for long glass fiber reinforced materials the welding factor for injection molded parts $(0.42)$ can be increased 
TABLE 7: Material strength.

\begin{tabular}{lcc}
\hline & \multicolumn{2}{c}{ Material strength $[\mathrm{MPa}]$} \\
& $\begin{array}{c}\text { Plates for hot plate } \\
\text { welding }\end{array}$ & $\begin{array}{c}\text { Plates for vibration } \\
\text { welding }\end{array}$ \\
\hline PP-GF30 & $68.18( \pm 0.75)$ & $60.13( \pm 0.79)$ \\
PP-LGF30 & $61.21( \pm 1.25)$ & $51.08( \pm 1.60)$ \\
PA-GF30 & $102.74( \pm 1.14)$ & $120.54( \pm 3.02)$ \\
PA-GF30EF & $120.81( \pm 2.00)$ & $111.02( \pm 1.67)$ \\
\hline
\end{tabular}

to 0.61 by welding parts with fibers being oriented initially longitudinally to the joining direction. In vibration welding, the highest welding factors are attained for injection molded plates without any further preparation (0.56 for PP-GF30, 0.37 for PP-LGF30, and 0.67 for PA-GF30) except for PAGF30EF. The maximum welding factor for longitudinal initial fiber orientation is 0.50 slightly higher than for injection molded plates with 0.47 . Obviously, the maximum welding factors in vibration welding are lower than in hot plate welding.

3.2. Effect on Fiber Orientation. In order to explain the different weld strength for different initial fiber orientations, the fiber orientation in the weld is analyzed.

3.2.1. Hot Plate Welding. When comparing the fiber orientation in the weld (Figure 17) with the initial fiber orientation in an injection molded plate without any further preparation (Figure 5), the change of the fiber orientation due to the welding process can be analyzed. The upper charts depict the fiber orientation over the part thickness (along the $x$ axis). A different progress of the components of the fiber orientation tensor after welding is only observed in the edge areas. Comparing the values for the components of the fiber orientation tensor near the edge $(x=0.9$ in the nonwelded part) and near the transition to the weld bead ( $x=1.0$ in the welded part) shows an increase of $a_{x x}$ of $173 \%$ due to the welding process. Fiber orientation in the joining direction $\left(a_{y y}\right)$ decreases by about $55 \%$. This shows the high influence of squeeze flow which leads to a reorientation of fibers into the $x$-direction, that is, into the bead. Additionally, $a_{z z}$ increases by about $27 \%$. Similar results are observed for the other materials.

Taking a look at the progress of the fiber orientation along the $y$-direction, the weld is easily detectable. $a_{x x}$ is higher in the weld than beyond the welding area while $a_{y y}$ and $a_{z z}$ are lower. The progress of $a_{x x}, a_{y y}$, and $a_{z z}$ in the $y$-direction towards the weld is similar to the orientation in the welding part towards the end of the flow path: $a_{x x}$ increases while $a_{y y}$ and $a_{z z}$ decrease. But the change of the fiber orientation is even more pronounced due to welding: $a_{x x}$ is about $60 \%$ higher than in the injection molded part at the end of the flow path, while $a_{y y}$ is $13 \%$ lower and $a_{z z}$ is $26 \%$ lower. This tendency is also valid for the other materials. But the decrease of $a_{y y}$ is more pronounced for short glass fiber reinforced material: $a_{y y}$ in the weld is about 40 to $50 \%$ less than in the joining plane of the part to be welded.
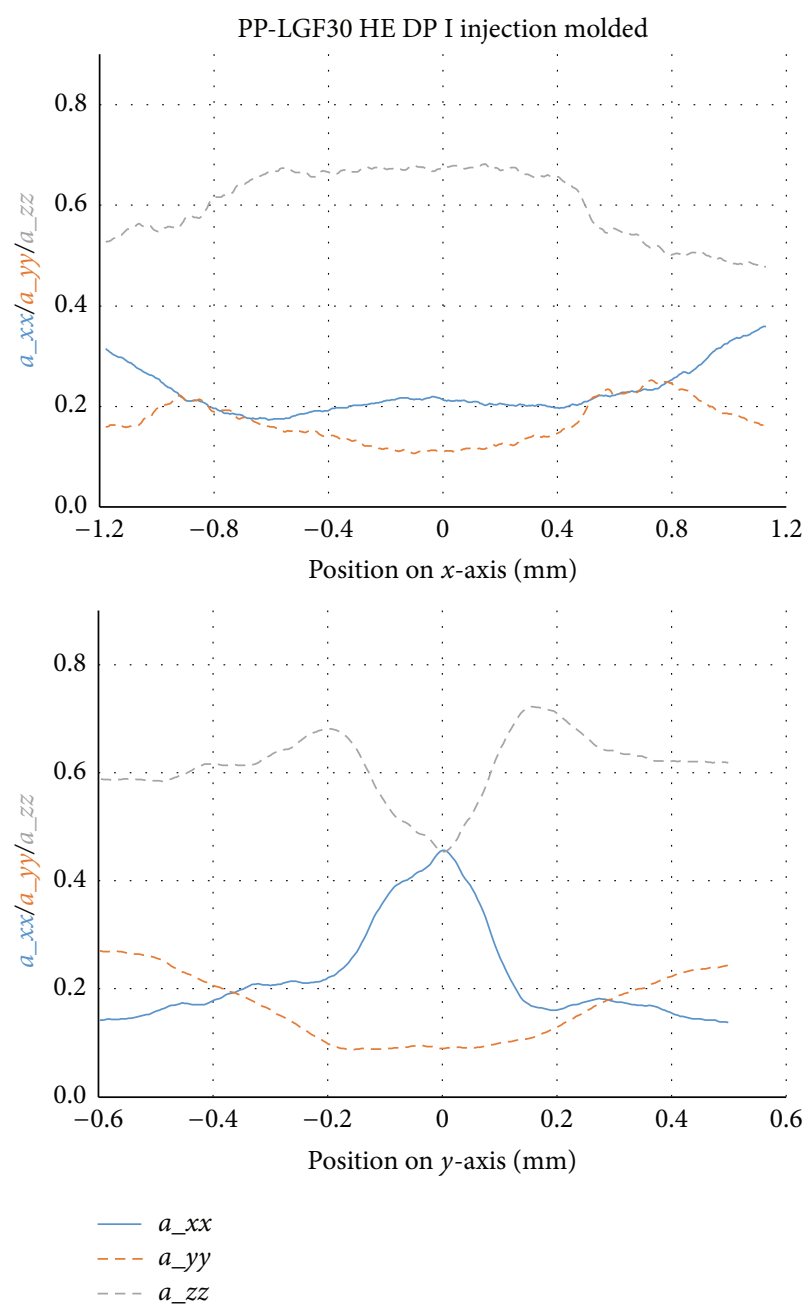

FIGURE 17: Progress of the fiber orientation along the $x$ - and $y$-axis in the weld of injection molded plates in hot plate welding of PPLGF30.

Due to the low fiber orientation in the joining direction in the part at the end of the flow path, where the weld is located generally, it seems logical that the proportion of fibers oriented in the joining direction in the weld is comparably low.

The fiber orientation in the weld (Figure 18) compared to the fiber orientation in the part to be welded with initial fiber orientation being longitudinal to the joining direction (Figure 9) shows similar tendencies as for injection molded plates. The orientation over the part thickness (along the $x$ direction) changes only in the edge areas due to welding. $a_{x x}$ increases in the welding process because fibers are reoriented from the $y$ - to the $x$-direction. Because of the high orientation in the $y$-direction of the part to be welded, $a_{y y}$ is still quite high in the weld in the middle of the part. Compared to the injection molded plates without any further preparation, $a_{y y}$ is nearly four times higher here.

Looking at the progress of the fiber orientation along the $y$-direction, the weld is clearly detectable. $a_{x x}$ is higher in the weld than beyond the weld zone and $a_{y y}$ and $a_{z z}$ are lower. 

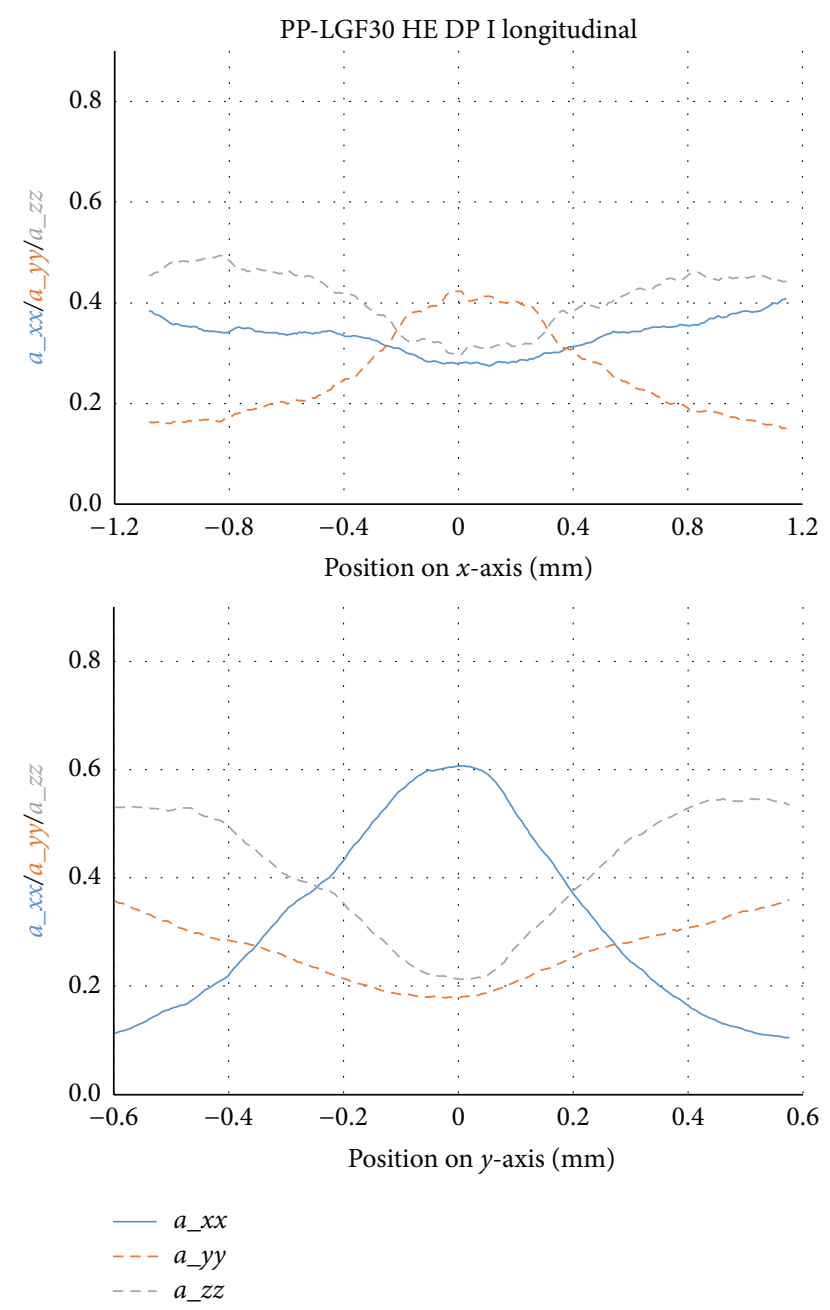

FIGURE 18: Progress of the fiber orientation along the $x$-and $y$-axis in the weld of two plates in hot plate welding of PP-LGF30 with initial fiber orientation being longitudinal to the joining direction.

Although the weld is located in an area of the part where many fibers are oriented longitudinally to the joining direction, $a_{y y}$ decreases significantly due the squeeze flow in welding: while in the part to be welded $a_{y y}$ was 0.47 , it is only 0.18 in the weld. In contrast, $a_{x x}$ increases during welding so that it is three times higher in the weld than in the part to be welded. $a_{z z}$ decreases slightly during welding. Since these results are also determined for the other materials, it is clearly shown that the reorientation of fibers occurs in hot plate welding even for "good" fiber orientation in the part before welding with a high share of fibers oriented in the joining direction. While more fibers in the weld are still oriented in the joining direction compared to the parts to be welded with fiber orientation resulting from injection molding, the fiber orientation in $x$ direction is higher as well. So, the "better" fiber orientation is partly compensated by a higher fiber orientation in the squeeze flow direction.

An increase of the fiber orientation in the direction of the squeeze flow in welding is also observed for parts with an initial fiber orientation being transverse to the joining
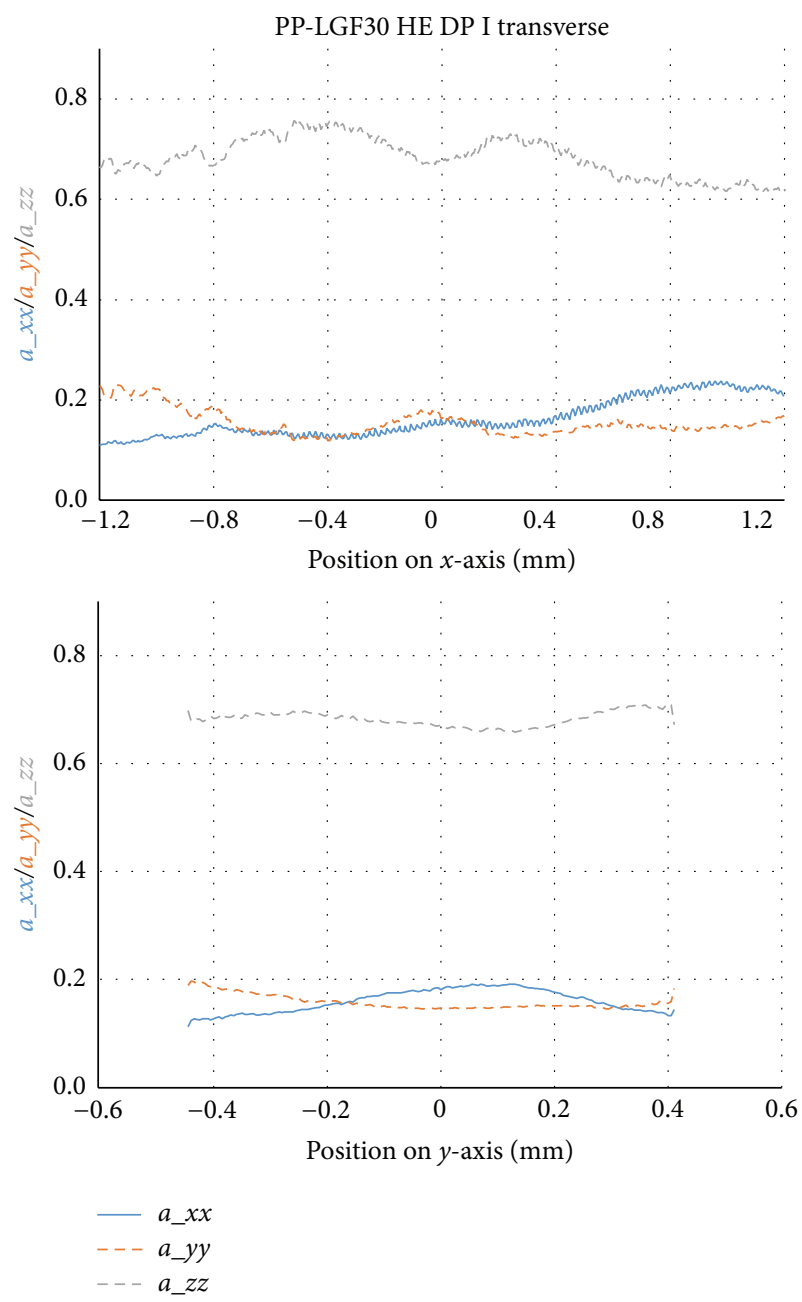

FIgURE 19: Progress of the fiber orientation along the $x$ - and $y$-axis in the weld of two plates in hot plate welding of PP-LGF30 with initial fiber orientation being transverse to the joining direction.

direction (Figures 10 and 19). In the middle of the part, the fiber orientation does not change.

In contrast to the results above, the weld is not clearly detectable in the progress of the fiber orientation along the $y$ axis. $a_{x x}$ increases only slightly due to a slight decrease of $a_{z z}$. $a_{y y}$ in the weld is just as high as in the part to be welded. The squeeze flow in welding does not affect the fiber orientation when the initial fiber orientation is transversely to the joining direction for PP-LGF30. For short glass fiber reinforced materials, the reorientation of fibers due to squeeze flow is more pronounced. But the increase of $a_{x x}$ can be ascribed to the decrease of $a_{z z}$ as well, the orientation in the $y$-direction does not change significantly.

As already shown in Figure 15, it is possible to attain a higher weld strength with a higher proportion of fibers oriented in the joining direction in the part to be welded. Figure 20 illustrates that fibers in the weld with initial longitudinal fiber orientation are more strongly oriented in the joining direction than for fiber orientation resulting from injection molding in the part to be joined. A high $a_{y y}$ in the 


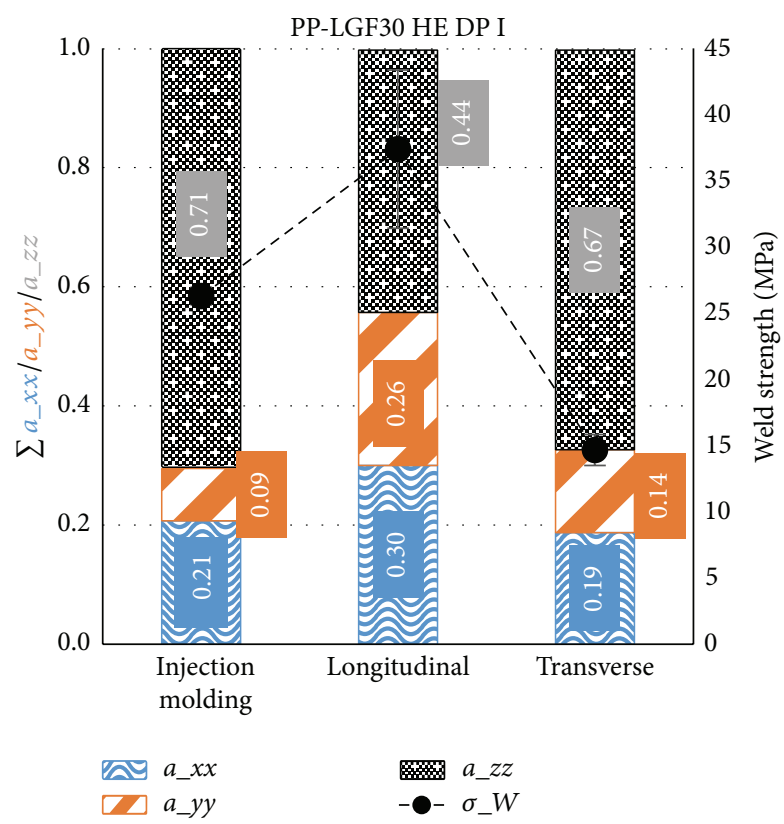

FIGURE 20: Fiber orientation and weld strength in hot plate welding of PP-LGF30 for different initial fiber orientations.

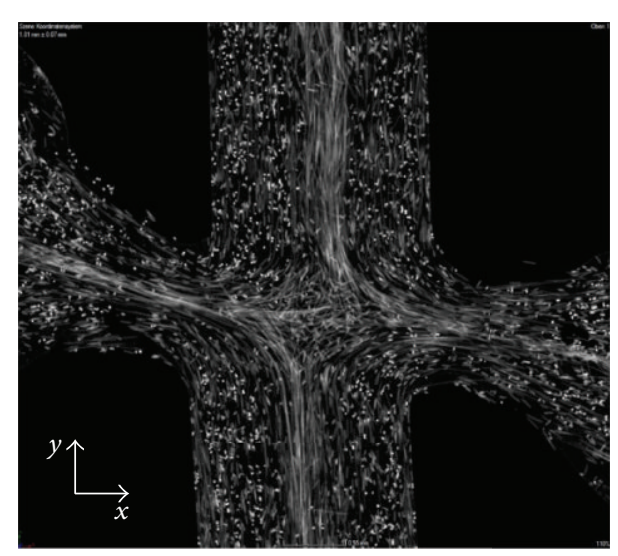

FIgURE 21: CT picture of the weld of PP-LGF30 with initial fiber orientation being longitudinal to the joining direction (DP I).

weld enables a high weld strength. However, the orientation in the joining direction cannot be the only influencing factor. Although $a_{y y}$ is higher with an initial transverse fiber orientation, the weld strength is lower compared to injection molded parts.

In Figure 21, a CT picture of the fiber orientation in the weld is shown for initial longitudinal fiber orientation. Figure 22 shows the fiber orientation in the weld for parts with a fiber orientation resulting from injection molding at the same welding parameters. In the first case, there is an area in the middle of the weld with several fibers still being oriented in the joining direction. The flow rate of the squeeze flow is low to zero in the middle of the joining part (Figure 1). Consequently, the reorientation in the middle is quite low. The fiber orientation longitudinal to the joining direction in the nonwelded part is kept up

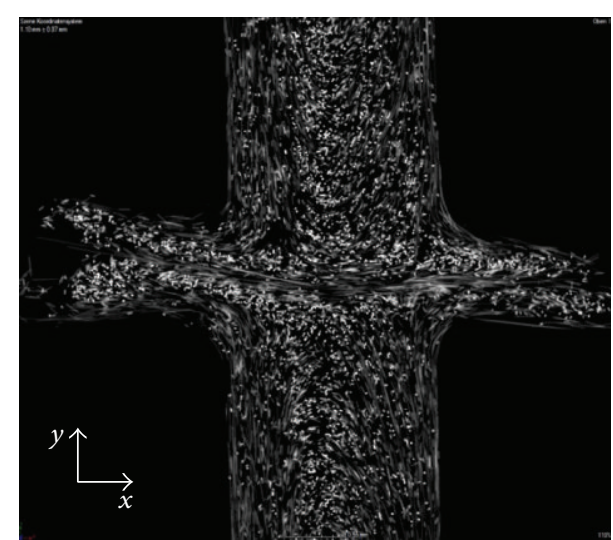

FIGURE 22: CT picture of the weld of PP-LGF30 with fiber orientation resulting from injection molding at the end of the flow path (DP I).

during welding. Some fibers even bridge the weld which results in a high weld strength. In contrast, in the middle of an injection molded part without any further preparation, the fibers are only oriented transversely to the joining direction. Longitudinally oriented fibers are only present between the middle and the edges of the part. These areas are subjected to higher flow rates in the squeeze flow, as illustrated in Figure 1. Consequently, these fibers are being reoriented towards the squeeze flow direction in welding and are therefore oriented transversely to the joining direction in the weld. The fiber orientation in the middle of the weld is an explanation for the different weld strengths. Initially longitudinally oriented fibers enable fiber bridging in the weld and therefore higher weld strength for long glass fiber reinforced PP.

In hot plate welding of short glass fiber reinforced PP, the fiber orientation in $y$-direction is also higher with an initial fiber orientation being longitudinal to the joining direction (Figure 23). However, in contrast to long glass fiber reinforced $\mathrm{PP}$, a higher weld strength is not attainable in spite of a higher $a_{y y}$. Weld strength for injection molded parts is higher than for parts with fibers being oriented initially longitudinally to the joining direction which in turn results in a higher weld strength than initial transverse fiber orientation. These results are also valid for the considered polyamides. Since the results of the polyamide types with different melt viscosity do not differ significantly, it is concluded that the melt viscosity does not influence the reorientation of fibers in squeeze flow.

CT analysis of the weld of short glass fiber reinforced materials confirms the results for long glass fiber reinforced PP. Figure 24 shows the fiber orientation in the weld for PAGF30EF with initial fiber orientation being longitudinal to the joining direction. There is also an area in the middle of the weld where fibers are still oriented longitudinally to the joining direction and some fibers even bridge the weld. But in contrast to PP-LGF30, the fiber bridging does not result in a higher weld strength for short glass fiber reinforced materials (Figure 15). 


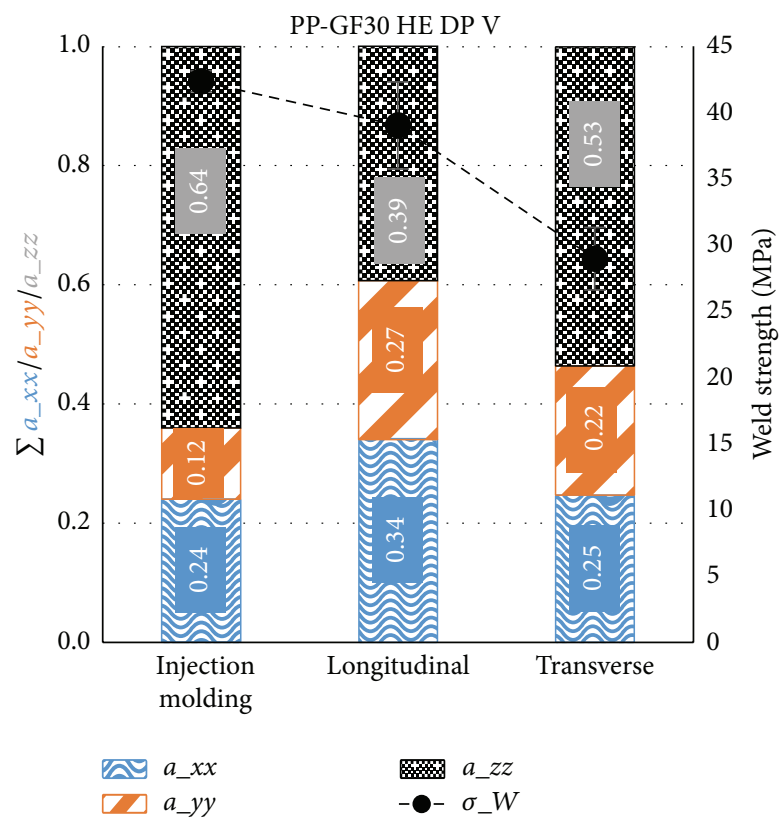

FIGURE 23: Fiber orientation and weld strength in hot plate welding of PP-GF30 for different initial fiber orientations.

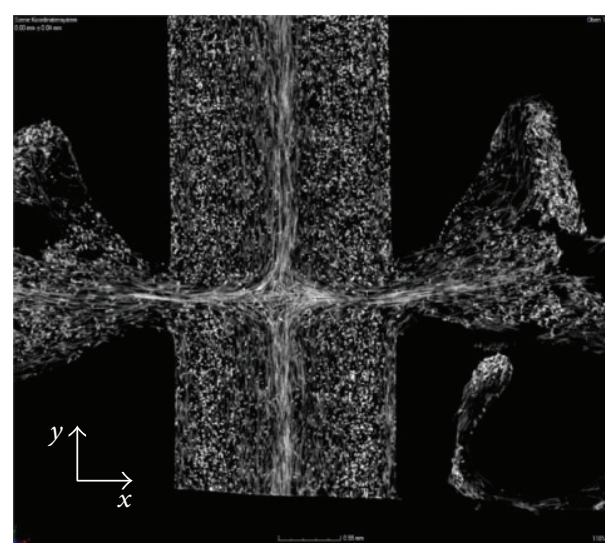

FIGURE 24: CT picture of the weld of PA-GF30EF with initial fiber orientation being longitudinal to the joining direction (DP I).

3.2.2. Vibration Welding. In contrast to hot plate welding, a significant increase of $a_{x x}$ due to welding is not determined in vibration welding. For injection molded plates made of PPLGF30, $a_{x x}$ increases only slightly from 0.19 (Table 2) to 0.21 in the weld for some welding parameters (Figure 25), while it even decreases to 0.14 for other welding parameters. The same is detectable for other materials. $a_{y y}$ decreases up to $20 \%$ in welding, while $a_{z z}$ increases up to $20 \%$. The increase of fiber orientation in the vibration direction ( $z$-direction) at the expense of the fiber orientation in the joining direction ( $y$-direction) is not that pronounced for short glass fiber reinforced materials but still significant. In contrast to hot plate welding, the weld is not easily detectable by looking at the progress of the fiber orientation along the $y$-axis. $a_{x x}$ is only slightly higher in the weld than beyond the welding area.
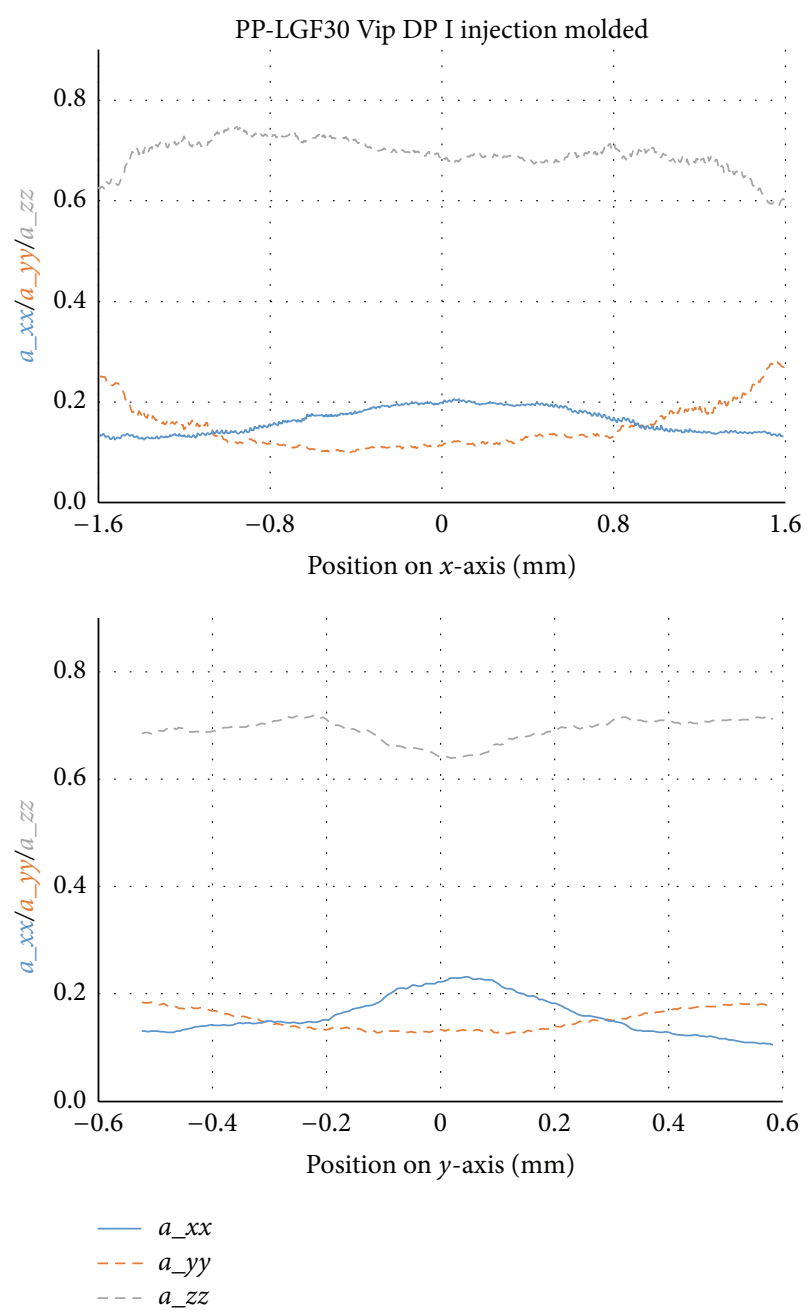

FIGURE 25: Progress of the fiber orientation along the $x$-and $y$-axis in the weld of injection molded plates in vibration welding of PPLGF30.

Since previous investigations have shown that the welding displacement does not affect the fiber orientation in the weld significantly, it is suitable that for injection molded parts design point I is considered while in the following analysis DP III is considered.

For parts with an initial fiber orientation being longitudinal to the joining direction, welding does not change the fiber orientation as distinctly as in hot plate welding (Figure 26). $a_{x x}$ decreases by about $10 \%$ while $a_{z z}$ increases by about $10 \%$. The fiber orientation in the joining direction is similar in the parts to be welded and in the weld.

In the weld of parts with initial fiber orientation being transverse to the joining direction, $a_{z z}$ with 0.7 is significantly higher than in the parts before welding with 0.47 (Figure 27). $a_{x x}$ and $a_{y y}$ decrease up to $50 \%$ and $35 \%$, respectively.

In contrast to hot plate welding, the squeeze flow plays a tangential role in the reorientation of fibers during vibration welding. A systematic increase of $a_{x x}$ is not detectable. $a_{z z}$ increases during welding on the expense of $a_{y y}$ and $a_{x x}$. The reorientation effect of the vibration motion is more 

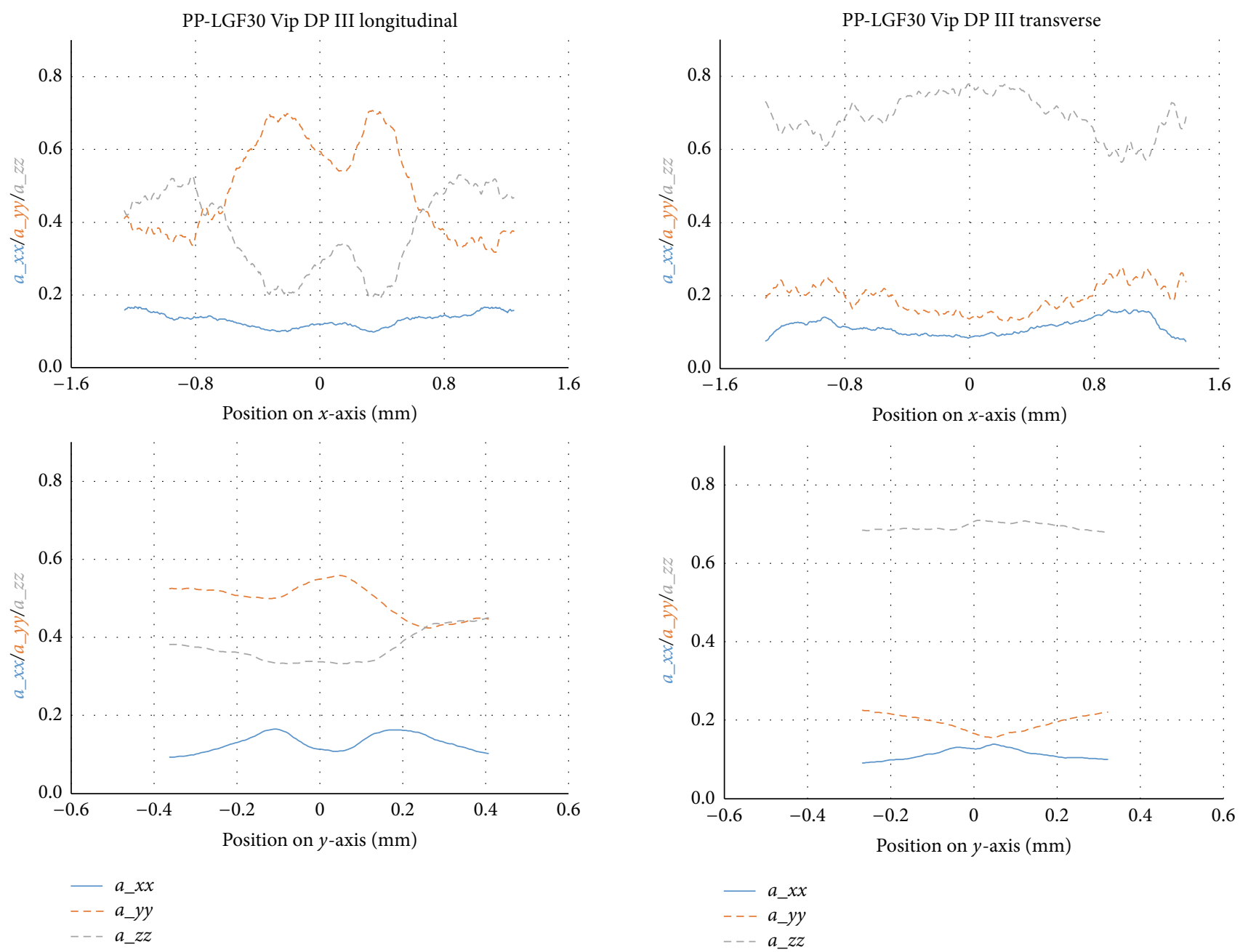

FIgURE 26: Progress of the fiber orientation along the $x$-and $y$-axis in the weld of two plates in vibration welding of PP-LGF30 with initial fiber orientation being longitudinal to the joining direction.

prominent compared to the squeeze flow. Another difference to hot plate welding is apparent when looking at the progress of the fiber orientation along the $y$-axis. The remaining melt layer in vibration welding is much smaller than in hot plate welding. Therefore the weld is not easy to detect by changes in the fiber orientation.

Figure 28 shows that the weld strength with initial fiber orientation being longitudinal to the joining direction is lower than for injection molded parts in spite of higher fiber orientation in the joining direction. For PP-LGF30, initial fiber orientation being transverse to the joining direction results in a significantly lower weld strength. For the short glass fiber reinforced materials, the attainable weld strength is independent of the initial fiber orientation (Figure 29). The weld strength for sawn plates tends to be lower than for injection molded plates without any further preparation.

Figure 30 shows a CT image of the weld of two plates with initial fiber orientation being longitudinal to the joining direction for PP-GF30. This picture does not differ from pictures for the short glass fiber reinforced polyamides. In

FIGURE 27: Progress of the fiber orientation along the $x$-and $y$-axis in the weld of two plates in vibration welding of PP-LGF30 with initial fiber orientation being transverse to the joining direction.

contrast to hot plate welding, there are no visible fibers that are oriented in the joining direction. Therefore, no fibers bridge the weld. Most fibers in the weld are visible as dots, which means that they are oriented perpendicular to the $x y$ plane in the $z$-direction. The fibers that have been oriented in the $y$-direction in the part before welding are being reoriented during welding by the vibration in the $z$-direction. There are no visible fibers that are oriented in the $x$-direction in the weld.

\section{Conclusion}

In most applications, the weld is placed at the end of the flow path of injection molded parts. In this area, fibers are usually oriented perpendicular to the flow direction of the melt in injection molding. Due to this characteristic fiber orientation it seems hard to realize an advantageous fiber orientation in the weld which corresponds to a high proportion of fibers oriented in the joining direction. Therefore, the parts to be joined were prepared to attain a special initial fiber 


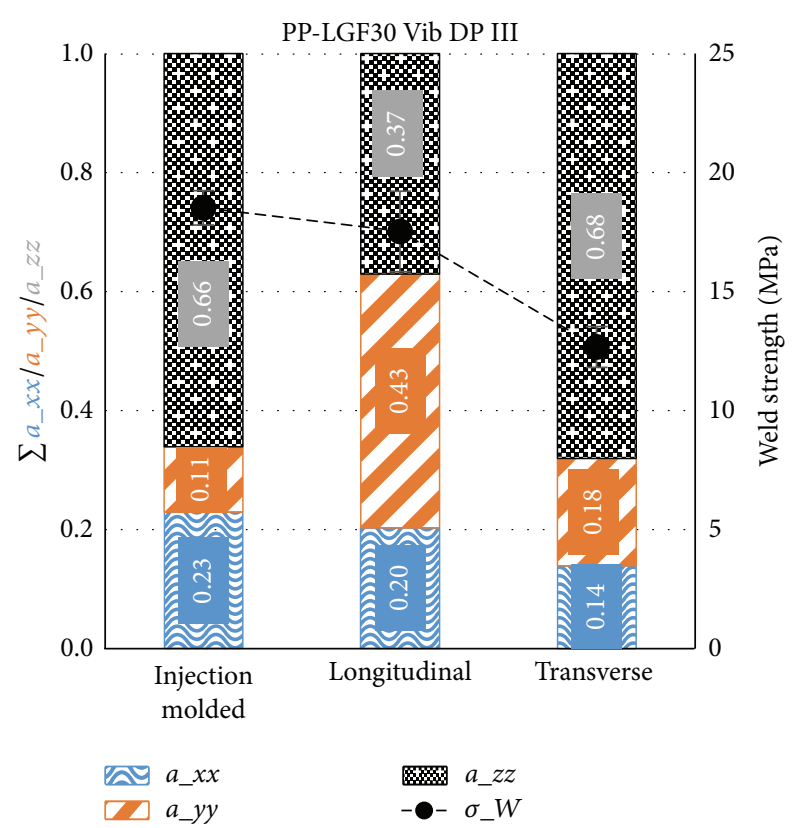

FIGURE 28: Fiber orientation and weld strength in vibration welding of PP-LGF30 for different initial fiber orientations.

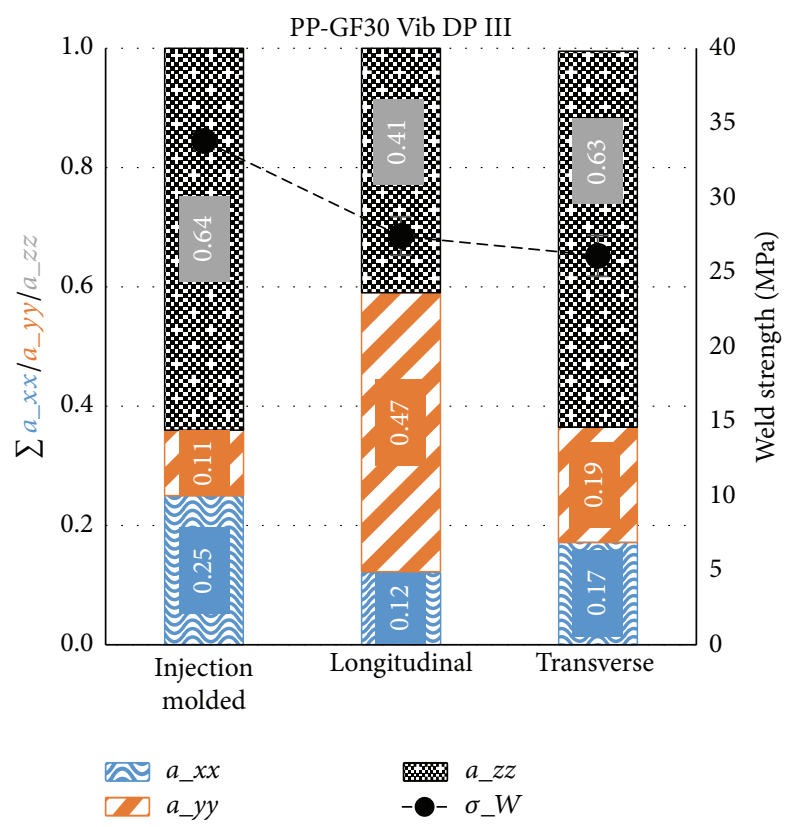

FIGURE 29: Fiber orientation and weld strength in vibration welding of PP-LGF30 for different initial fiber orientations.

orientation in the joining area: parts with a high proportion of fibers oriented longitudinally or transversely to the joining direction. The weld strength and the fiber orientation in the weld were analyzed for different initial fiber orientations.

In hot plate welding of long glass fiber reinforced PP for parts to be joined with a high initial fiber orientation being longitudinal to the joining direction a higher weld strength was attained than for joining parts with fiber orientation resulting from injection molding in the end of the flow path.

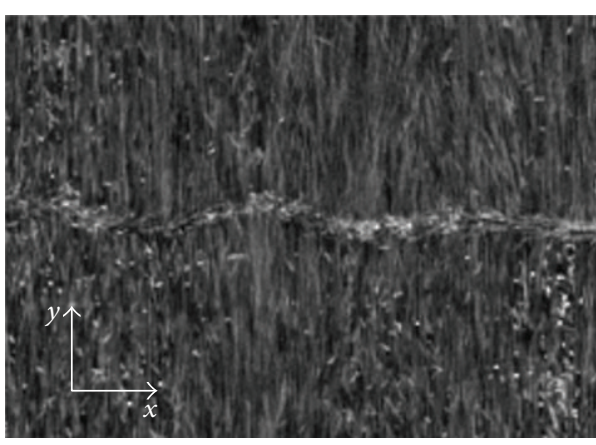

FIGURE 30: CT picture of the weld of PP-GF30 with initial fiber orientation being longitudinal to the joining direction (DP V).

The higher weld strength can be ascribed to a higher fiber orientation in the weld. In the middle of the joined parts, fibers are even bridging the weld. Fiber bridging only results in higher weld strength for long glass fiber reinforced PP; in short glass fiber reinforced materials the weld strength cannot be increased with a higher initial fiber orientation being longitudinal to the joining direction. Nevertheless, the reorientation of fibers into the $x$-direction, that is, into the bead, due to the squeeze flow in welding occurs independently of the initial fiber orientation. The more the fibers are oriented initially longitudinally to the joining direction, the more the increase of fiber orientation in the $x$-direction in welding is pronounced. This means that the higher advantageous fiber orientation in the joining direction might be partly compensated by a more pronounced fiber reorientation due to squeeze flow. A high $a_{y y}$ in the weld enables a high weld strength but it is not the only influencing factor.

In vibration welding, an initial fiber orientation being longitudinal to the joining direction does not result in higher weld strength for long or for short glass fiber reinforced materials. The initial fiber orientation does not affect the weld strength as distinctly as in hot plate welding. The reason is the different reorientation effects in vibration welding compared to hot plate welding. In contrast to hot plate welding, the squeeze flow plays a tangential role in the reorientation of fibers during vibration welding. The vibration motion in combination with the welding pressure results in increasing fiber orientation in the vibration direction during welding independent of the initial fiber orientation.

We have shown that a higher weld strength in hot plate welding is attainable with a high initial fiber orientation in the joining direction in the joining area at least for long glass fiber reinforced materials: the welding factor can be increased by about $45 \%$. This shows the importance of efforts in injection molding to attain high fiber orientation in the flow direction in the areas where the weld is intended to be located.

\section{Competing Interests}

The authors declare no competing interests regarding the publication of this paper. 


\section{Acknowledgments}

The IGF Project $18702 \mathrm{~N}$ of the research association "Forschungsvereinigung Schweißen und verwandte Verfahren e. V. des DVS, Aachener Straße 172, 40223 Düsseldorf" was, on the basis of a resolution of the German Bundestag, promoted by the German Ministry of Economic Affairs and Energy via AiF within the framework of the program for the promotion of joint industrial research and development (IGF).

\section{References}

[1] AVK-Industrievereinigung Verstärkte Kunststoffe Handbuch Faserverbund-kunststoffeComposites-Grundlagen, Verarbeitung, Anwendung. Springer Fachmedien, Wiesbaden, 4. Auflage, 2014.

[2] H. Schuermann, Konstruieren Mit Faser-Kunststoff-Verbunden, Springer, Berlin, Germany, 2005.

[3] D. A. Grewell, A. Benatar, and J. B. Park, Plastics and Composites Welding Handbook, Carl Hanser, München, Germany, 2003.

[4] A. Bruessel, Fertigungstechnische und werkstoffspezifische Aspekte zum Fügen von Thermoplasten mittels Heizelement [Ph.D. dissertation], Universität-Gesamthochschule Paderborn, 1999.

[5] V. Kagan, "Optimized mechanical performance of welded and molded butt joints: part I-similarities and differences," Journal of Reinforced Plastics and Composites, vol. 22, no. 9, pp. 773-784, 2003.

[6] M. Gehde, M. Giese, and G. W. Ehrenstein, "Welding of thermoplastics reinforced with random glass mat," Polymer Engineering and Science, vol. 37, no. 4, pp. 702-714, 1997.

[7] B. Baudrit, Entwicklung innovativer Technologien zum Heizelement-stumpf- und Infrarot-Schweißen von mineralgefüllten und faserverstärkten Kunststoffen. Forschungs-bericht der SKZ-KFE gGmbH Kunststoff-Forschung und-Entwicklung zu dem AiF-geförderten Vorhaben 17303 N, 2014.

[8] C. B. Bucknall, I. C. Drinkwater, and G. R. Smith, "Hot plate welding of plastics: factors affecting weld strength," Polymer Engineering and Science, vol. 20, no. 6, pp. 432-440, 1980.

[9] H. Potente, J. Natrop, T. K. Pedersen, and M. Uebbing, "Comparative investigations into the welding of glass-fiber-reinforced PES," Journal of Thermoplastic Composite Materials, vol. 6, no. 2, pp. 147-159, 1993.

[10] V. Kagan, S. Lui, G. Smith, and J. Patry, "The optimized performance of linear vibration welded nylon 6 and nylon 66 butt joints," in Proceedings of the International SPE Annual Technical Conference (ANTEC '96), vol. 1, pp. 1266-1274, 1996.

[11] P. Bates, D. Couzens, and J. Kendall, "Vibration welding of continuously reinforced thermoplastic composites," Journal of Thermoplastic Composite Materials, vol. 14, no. 4, pp. 344-354, 2001.

[12] S.-J. Liu and H.-F. Cheng, "The influence of interface geometry on the joint strengths of hot plate welded composites," Journal of Reinforced Plastics and Composites, vol. 29, no. 4, pp. 497-509, 2010.

[13] S. G. Advani and C. L. Tucker, "The use of tensors to describe and predict fiber orientation in short fiber composites," Journal of Rheology, vol. 31, no. 8, pp. 751-784, 1987.

[14] R. S. Bay and C. L. Tucker, "Stereological measurement and error estimates for three-dimensional fiber orientation," in Polymer Engineering and Science, vol. 32, no. 4, pp. 240-253, Wiley-VCH Verlag, Weinheim, Germany, 1992.
[15] R. S. Bay and C. L. Tucker, "Fiber orientation in simple injection moldings. Part II: experimental results," Polymer Composites, vol. 13, no. 4, pp. 332-341, 1992.

[16] G. Menges and P. Geisbüsch, "Die Glasfaserorientierung und ihr Einfluß auf die mechanischen Eigenschaften thermoplastischer Spritzgießteile-Eine Abschätzmethode," Colloid \& Polymer Science, vol. 260, no. 1, pp. 73-81, 1982.

[17] F. Johannaber and W. Michaeli, Handbuch Spritzgießen, Carl Hanser, München, Germany, 2nd edition, 2004.

[18] F. Folgar and C. L. Tucker, "Orientation behavior of fibers in concentrated suspensions," Journal of Reinforced Plastics and Composites, vol. 3, no. 2, pp. 98-119, 1984.

[19] T. Aurich, Spritzgießen und resultierende Verbundeigenschaften von flachsfaser-verstärktem Polypropylen [Dissertation], Technische Universität Chemnitz, Chemnitz, Germany, 2000.

[20] J. Kreiter, Optimierung der Schweißnahtfestigkeit von Heizelementstumpfschweißungen von Formteilen durch verbesserte Prozessführung und Selbsteinstellung [Dissertation], UniversitätGesamthochschule Paderborn, 1988.

[21] "DVS Heizelementschweißen von Formteilen aus thermoplastischen Kunststoffen in der Serienfertigung," Richtlinie DVS 2215-1, 2010.

[22] A. K. H. Schlarb, Zum Vibrationsschweißen von Polymerwerkstoffen-Prozeß-Struktur-Eigenschaften [Ph.D. dissertation], Universität-Gesamthochschule Kassel, 1989.

[23] "DVS Vibrationsschweißen von Formteilen und Halbzeugen aus thermoplastischen Kunst-stoffen in der Serienfertigung," Richtlinie DVS 2217-1, 1999. 

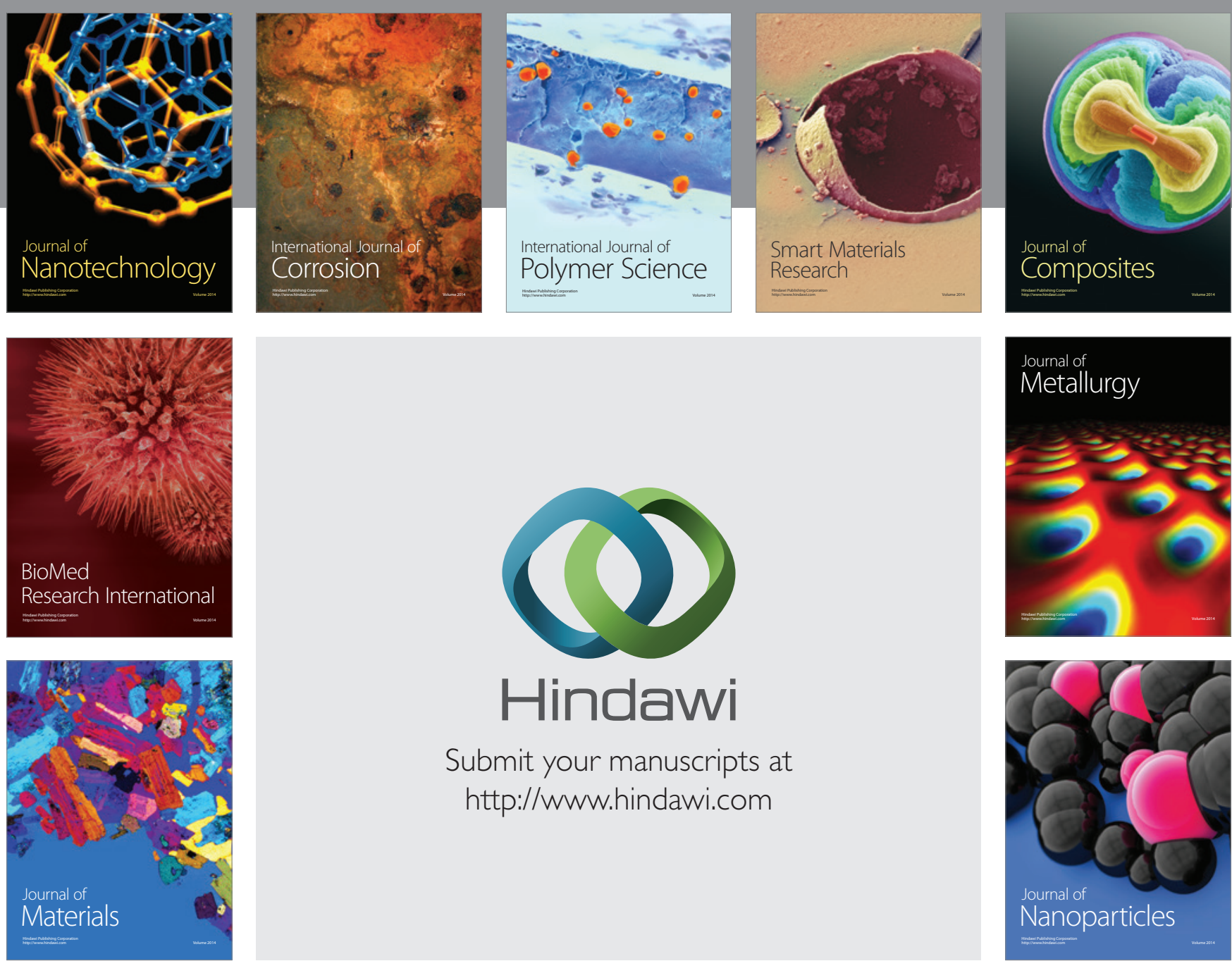

\section{Hindawi}

Submit your manuscripts at

http://www.hindawi.com

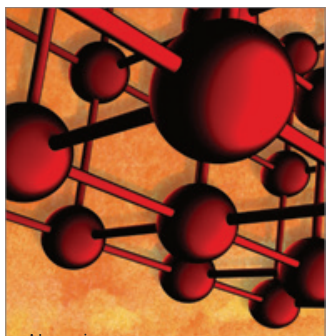

Materials Science and Engineering
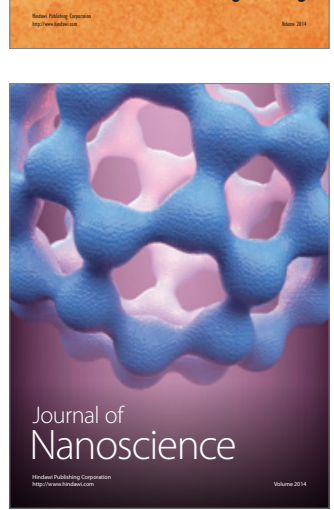
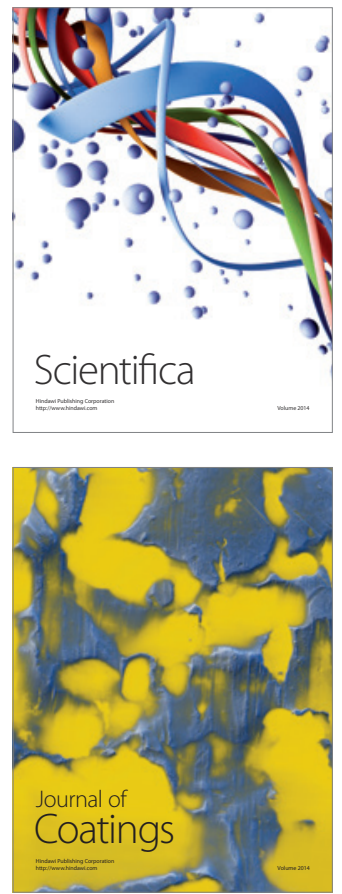
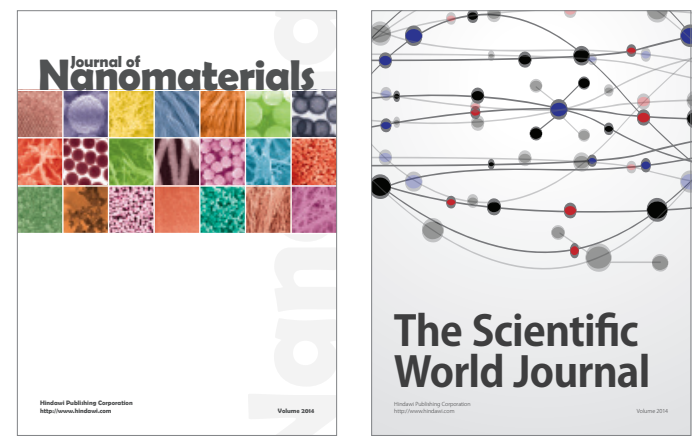

The Scientific World Journal
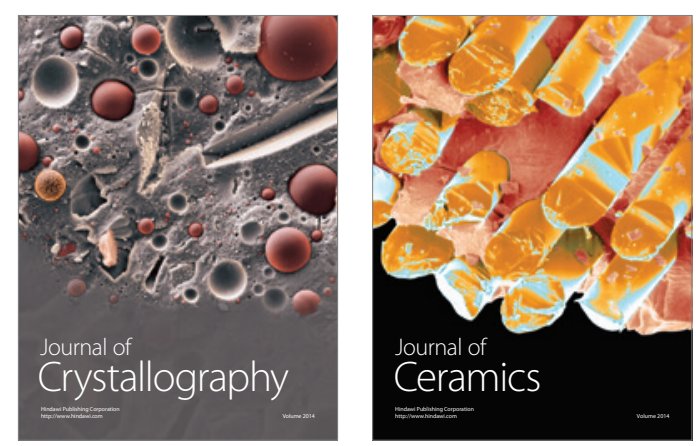
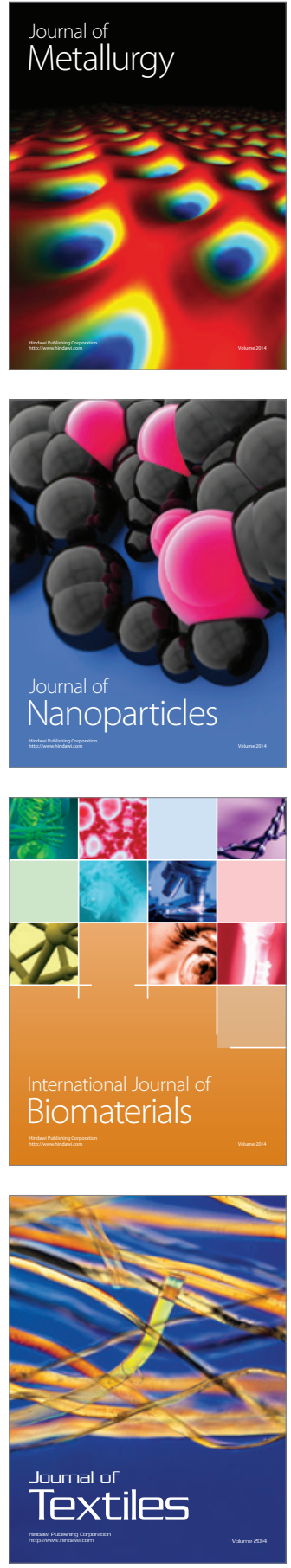